\title{
Critical Evaluation of Rate Constants and Equilibrium Constants of Hydrogen Peroxide Photolysis in Acidic Aqueous Solutions Containing Chloride lons ${ }^{\text {a) }}$
}

\author{
Xiao-Ying $\mathbf{Y u}^{\mathrm{b})}$ \\ Department of Chemistry, The University of Michigan, Ann Arbor, Michigan 48109-1055
}

(Received 9 August 2003; revised manuscript received 26 January 2004; accepted 2 February 2004; published online 13 August 2004)

Equilibrium constants and rate constants involving $\mathrm{Cl} \cdot(\mathrm{aq}), \mathrm{Cl}^{-}, \mathrm{Cl}_{2}^{-} \cdot(\mathrm{aq}), \mathrm{HO} \cdot \mathrm{H}_{2} \mathrm{O}$, and $\mathrm{H}_{2} \mathrm{O}_{2}$ (aq) determined at $297 \pm 2 \mathrm{~K}$ in the aqueous phase are updated and evaluated. Most of the rate constants and equilibrium constants are obtained by either pulse radiolysis or laser flash photolysis. The recommended values of rate constants and equilibrium constants are achieved by un-weighted averaging of the reliable experimental measurements. (C) 2004 American Institute of Physics. [DOI: 10.1063/1.1695414]

Key words: aqueous phase; chloride; chlorine; critical evaluation; dichlorine radical anion; equilibrium constant; free radical; hydrogen peroxide; rate constant; room temperature.

\section{Contents}

1. Introduction. ..................... 747

2. General Methods.................... 749

3. Guide to the Data Sheets................ 749

3.1. Conventions Concerning Rate Constants.... 750

3.2. Arrangement of Tables.............. 750

3.3. Data Evaluation................... 750

4. Data Sheets..................... 750

4.1. $k_{2}, \mathrm{HO} \cdot+\mathrm{H}_{2} \mathrm{O}_{2} \rightarrow \mathrm{HO}_{2} \cdot+\mathrm{H}_{2} \mathrm{O} \cdot \ldots \ldots \ldots, 750$

4.1.1. Direct Method................ 750

4.1.2. Indirect Method............... 751

4.2. $k_{3}, \mathrm{HO} \cdot+\mathrm{Cl}^{-} \rightarrow \mathrm{ClOH}^{-} \cdot \ldots \ldots \ldots \ldots \ldots .751$

4.2.1. Direct Method................ 751

4.2.2. Indirect Method............... 752

4.3. $K_{3}$ and $k_{-3}, \mathrm{ClOH}^{-} \cdot \rightarrow \mathrm{Cl}^{-}+\mathrm{HO} \cdot \ldots \ldots . \quad 753$

4.4. $k_{4} K_{3}, \mathrm{HO} \cdot+\mathrm{Cl}^{-}+\mathrm{H}^{+} \rightarrow \mathrm{Cl} \cdot+\mathrm{H}_{2} \mathrm{O} \ldots \ldots . \quad 753$

4.5. $K_{4}$ and $k_{4}, \mathrm{ClOH}^{-} \cdot+\mathrm{H}^{+} \rightarrow \mathrm{Cl} \cdot+\mathrm{H}_{2} \mathrm{O} \ldots . \quad 754$

4.6. $k_{-4}\left[\mathrm{H}_{2} \mathrm{O}\right], \mathrm{Cl} \cdot+\mathrm{H}_{2} \mathrm{O} \rightarrow \mathrm{ClOH}^{-} \cdot+\mathrm{H}^{+} \ldots . .754$

4.7. $k_{5}, k_{-5}$, and $K_{5}, \mathrm{Cl} \cdot+\mathrm{Cl}^{-} \leftrightarrow \mathrm{Cl}_{2}^{-} \cdot \ldots \ldots . \quad 755$

4.7.1. Forward Rate Constant $k_{5} \ldots \ldots \ldots .755$

4.7.2. Reverse Rate Constant $k_{-5} \ldots \ldots \ldots .756$

4.7.3. Equilibrium Constant $K_{5} \ldots \ldots \ldots \ldots 757$

4.8. $k_{6}, \mathrm{Cl}_{2}^{-} \cdot+\mathrm{Cl}_{2}^{-} \cdot \rightarrow 2 \mathrm{Cl}^{-}+\mathrm{Cl}_{2} \ldots \ldots \ldots \ldots .757$

4.9. $k_{7}, \mathrm{Cl} \cdot+\mathrm{Cl}_{2}^{-} \cdot \rightarrow \mathrm{Cl}^{-}+\mathrm{Cl}_{2} \ldots \ldots \ldots \ldots \ldots .759$

4.10. $k_{8}\left[\mathrm{H}_{2} \mathrm{O}\right], \mathrm{Cl}_{2}^{-} \cdot+\mathrm{H}_{2} \mathrm{O} \rightarrow \mathrm{ClOH}^{-} \cdot+\mathrm{H}^{+}$

$+\mathrm{Cl}^{-} \ldots \ldots \ldots \ldots \ldots \ldots \ldots \ldots \ldots \ldots \ldots \ldots$

4.11. $k_{9}, \mathrm{Cl}_{2}^{-} \cdot+\mathrm{H}_{2} \mathrm{O}_{2} \rightarrow \mathrm{HO}_{2} \cdot+\mathrm{H}^{+}+\mathrm{Cl}^{-} \ldots \ldots .761$

4.12. $k_{10}, \mathrm{Cl} \cdot+\mathrm{H}_{2} \mathrm{O}_{2} \rightarrow \mathrm{H}^{+}+\mathrm{Cl}^{-}+\mathrm{HO}_{2} \cdot \ldots \ldots .761$

4.13. $k_{11}, \mathrm{Cl}_{2}^{-} \cdot+\mathrm{HO}_{2} \cdot \rightarrow \mathrm{O}_{2}+\mathrm{H}^{+}+2 \mathrm{Cl}^{-} \ldots \ldots . \quad 761$

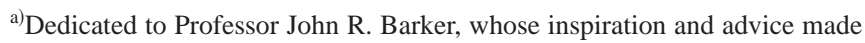
this work possible.

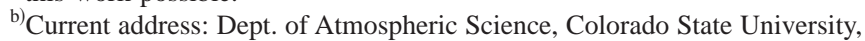
Fort Collins, CO 80523-1371; Electronic mail: yingybei@umich.edu or xiao-ying.yu@colostate.edu

(C) 2004 American Institute of Physics.
5. Conclusions......................... 762

6. Acknowledgments................... 763

7. References....................... 763

\section{List of Tables}

1. The preferred values of $k_{i}$ and $K_{i}$ in the photochemical system of $\mathrm{H}_{2} \mathrm{O}_{2}$ and $\mathrm{Cl}^{-}$in the aqueous phase at room temperature......... 748

2. Rate constant data of $k_{2}$ by (a) direct measurements and (b) competition kinetics..... 750

3. Rate constant data of $k_{3}$ by (a) direct measurements and (b) competition kinetics..... 752

4. Rate constant data of $k_{-3} \ldots \ldots \ldots \ldots \ldots .753$

5. Rate constant data of $k_{4} K_{3}$ by direct and competition kinetics.................... 753

6. Data of $K_{4}$ and $k_{4} \ldots \ldots \ldots \ldots \ldots \ldots \ldots \ldots \ldots$

7. Rate constant data of $k_{-4}\left[\mathrm{H}_{2} \mathrm{O}\right] \ldots \ldots \ldots \ldots .755$

8. Rate constant data of $k_{5}$ by direct measurements..................... 755

9. Rate constant data of $k_{-5}$ by direct measurements................... 756

10. Equilibrium constant data of $K_{5} \ldots \ldots \ldots \ldots \ldots 757$

11. Rate constant data of $k_{6} \ldots \ldots \ldots \ldots \ldots \ldots \ldots$

12. Rate constant data of $k_{7} \ldots \ldots \ldots \ldots \ldots \ldots . \ldots 759$

13. Rate constant data of $k_{8}\left[\mathrm{H}_{2} \mathrm{O}\right] \ldots \ldots \ldots \ldots \ldots, 760$

14. Rate constant data of $k_{9} \ldots \ldots \ldots \ldots \ldots \ldots . \ldots 76$

15. Rate constant data of $k_{10} \ldots \ldots \ldots \ldots \ldots \ldots . \ldots 761$

16. Rate constant data of $k_{11} \ldots \ldots \ldots \ldots \ldots . \ldots 761$

\section{Introduction}

The photochemical system involving $\mathrm{HO} \cdot(\mathrm{aq})$ and $\mathrm{Cl}^{-}$in the aqueous phase is of significant interest in the fundamental kinetics understanding and its application to atmospheric and biological sciences. Overall there have been more than 
70 independent research articles related to the chemical kinetics study of $\mathrm{Cl}_{2}^{-} \cdot(\mathrm{aq}) / \mathrm{Cl} \cdot(\mathrm{aq})$ in the aqueous phase in the past few decades. Although several previous reviews summarized the rate coefficient of aqueous phase free radical reactions, ${ }^{1-5}$ the most recent evaluations are dated in $1988 .{ }^{3,4}$ Since then, more research has been dedicated to the kinetics of free radicals of interest in atmospheric water phase specifically investigating the $\mathrm{Cl}_{2}^{-} \cdot(\mathrm{aq}) / \mathrm{Cl} \cdot(\mathrm{aq})$ mechanism. In contrast, there is a lack of in-depth analysis and critical evaluation of research findings relevant to the $\mathrm{Cl}^{-} / \mathrm{H}_{2} \mathrm{O}_{2} / \mathrm{hv}$ system in the aqueous phase. Hence, a critical review of the research papers in the past $40 \mathrm{yr}$ is needed to recognize past accomplishments, identify mistakes, refine rate constants and equilibrium constants, verify the validity of previous citations, improve the creditability of future citations, and clarify future research focus.

This review is the fourth paper of a series of papers designated to the kinetic and mechanistic investigation of the $\mathrm{Cl}^{-} / \mathrm{H}_{2} \mathrm{O}_{2} / \mathrm{hv}$ and $\mathrm{Cl}^{-} / \mathrm{S}_{2} \mathrm{O}_{8}^{2-} / \mathrm{hv}$ systems. We recently studied the chemical mechanism of the $\mathrm{HO} \cdot(\mathrm{aq})$ and $\mathrm{Cl}^{-}$ system $^{6,7}$ in the aqueous phase and reported a series of reaction rate constants and equilibrium constants involving $\mathrm{HO} \cdot(\mathrm{aq}), \mathrm{Cl} \cdot(\mathrm{aq}), \mathrm{Cl}^{-}, \mathrm{H}_{2} \mathrm{O}_{2}$, and $\mathrm{Cl}_{2}^{-} \cdot(\mathrm{aq})$. The first three papers deal with the kinetic and mechanistic analyses of our experimental data, and this paper evaluates the rate constants and equilibrium constants involved in the updated mechanism. As a result of our experimental findings, ${ }^{6,8}$ the hydrogen extraction reaction $\mathrm{Cl} \cdot($ aq $)+\mathrm{H}_{2} \mathrm{O}_{2} \rightarrow \mathrm{HO}_{2} \cdot($ aq $)+\mathrm{H}^{+}$ $+\mathrm{Cl}^{-}$is added to the mechanism. In addition, the reaction $\mathrm{Cl} \cdot(\mathrm{aq})+\mathrm{Cl}_{2}^{-} \cdot(\mathrm{aq}) \rightarrow \mathrm{Cl}^{-}+\mathrm{Cl}_{2}$ is confirmed to participate in the second-order decay of $\mathrm{Cl}_{2}^{-} \cdot(\mathrm{aq})$. Although our recent results are in fairly good agreement with previous findings, discrepancy still exists in certain rate constants and equilibrium constants. Therefore, it is necessary to evaluate the experimentally obtained kinetics data reported in the literature to discuss and estimate the uncertainty.

The review of reaction rate coefficients and equilibrium constants is focused on $\mathrm{Cl} \cdot(\mathrm{aq})$ related free radicals generated by photodissociation of hydrogen peroxide and its subsequent reactions with $\mathrm{Cl}^{-}$at room temperature, i.e., reactions (2)-(11). The preferred values of rate constant data and equilibrium constant data are summarized in Table 1 . The $K_{i}$ always refers to equilibrium constant for reaction $i$; and $k_{i}$ refers to reaction rate constants for reaction $i$. The (aq) is omitted in the following text for the simplicity of presentation. The numbering scheme of the reactions of interest is consistent throughout the paper. Farhataziz and Ross ${ }^{1}$ have detailed evaluation of $\mathrm{HO} \cdot$ and $\mathrm{HO}_{2} \cdot$ related reactions, i.e., reactions (12)-(16), which are included for completeness of the mechanism. Most of the reaction rate constants were determined by pulse radiolysis or flash photolysis. Values determined by other techniques were included when they seem reliable and when absolute rate constants could be derived from their reports. Relative rates are not included as such. All values presented in this paper were determined in aqueous or predominantly aqueous systems.

The equilibrium constant of reaction (5), $\mathrm{Cl} \cdot$
TABLE 1 . The preferred values of $k_{i}$ and $K_{i}$ in the photochemical system of $\mathrm{H}_{2} \mathrm{O}_{2}$ and $\mathrm{Cl}^{-}$in the aqueous phase at room temperature

\begin{tabular}{|c|c|c|}
\hline No. & Reaction & $k$ \\
\hline 1 & $\mathrm{H}_{2} \mathrm{O}_{2}+h \nu \rightarrow \mathrm{HO} \cdot+\mathrm{HO}^{\cdot}{ }^{\mathrm{a}}$ & $\Phi_{\mathrm{HO}}=1^{\mathrm{b}}$ \\
\hline 2 & $\mathrm{HO} \cdot+\mathrm{H}_{2} \mathrm{O}_{2} \rightarrow \mathrm{HO}_{2} \cdot+\mathrm{H}_{2} \mathrm{O}$ & $k_{2}=(3.2 \pm 1.5) \times 10^{7} \mathrm{M}^{-1} \mathrm{~s}^{-1}$ \\
\hline 3 & $\mathrm{HO} \cdot+\mathrm{Cl}^{-} \rightarrow \mathrm{ClOH}^{-}$ & $k_{3}=(4.2 \pm 0.2) \times 10^{9} \mathrm{M}^{-1} \mathrm{~s}^{-1}$ \\
\hline-3 & $\mathrm{ClOH}^{-} \cdot \rightarrow \mathrm{HO} \cdot+\mathrm{Cl}^{-}$ & $\begin{array}{l}k_{-3}=(6.0 \pm 1.1) \times 10^{9} \mathrm{~s}^{-1} \\
K_{3}=0.70 \pm 0.13 \mathrm{M}^{-1}\end{array}$ \\
\hline 4 & $\mathrm{ClOH}^{-} \cdot+\mathrm{H}^{+} \rightarrow \mathrm{Cl} \cdot+\mathrm{H}_{2} \mathrm{O}$ & $k_{4}=(2.4 \pm 0.4) \times 10^{10} \mathrm{M}^{-1} \mathrm{~s}^{-1}$ \\
\hline-4 & $\mathrm{Cl} \cdot+\mathrm{H}_{2} \mathrm{O} \rightarrow \mathrm{ClOH}^{-} \cdot+\mathrm{H}^{+}$ & $\begin{array}{l}k_{-4}\left[\mathrm{H}_{2} \mathrm{O}\right]=(1.8 \pm 0.6) \times 10^{5} \mathrm{~s}^{-1} \\
K_{4}=(7.4 \pm 2.8) \times 10^{6}\end{array}$ \\
\hline 5 & $\mathrm{Cl} \cdot+\mathrm{Cl}^{-} \rightarrow \mathrm{Cl}_{2}^{-}$ & $k_{5}=(7.8 \pm 0.8) \times 10^{9} \mathrm{M}^{-1} \mathrm{~s}^{-1}$ \\
\hline-5 & $\mathrm{Cl}_{2}^{-} \cdot \rightarrow \mathrm{Cl} \cdot+\mathrm{Cl}^{-}$ & $\begin{array}{l}k_{-5}=(5.7 \pm 0.4) \times 10^{4} \mathrm{~s}^{-1} \\
K_{5}=(1.4 \pm 0.2) \times 10^{5} \mathrm{M}^{-1}\end{array}$ \\
\hline 6 & $\mathrm{Cl}_{2}^{-} \cdot+\mathrm{Cl}_{2}^{-} \cdot \rightarrow 2 \mathrm{Cl}^{-}+\mathrm{Cl}_{2}$ & $k_{6}=(3.5 \pm 2.7) \times 10^{9} \mathrm{M}^{-1} \mathrm{~s}^{-1}$ \\
\hline 7 & $\mathrm{Cl} \cdot+\mathrm{Cl}_{2}^{-} \cdot \rightarrow \mathrm{Cl}^{-}+\mathrm{Cl}_{2}$ & $k_{7}=(1.4 \pm 1.0) \times 10^{9} \mathrm{M}^{-1} \mathrm{~s}^{-1}$ \\
\hline 8 & $\mathrm{Cl}_{2}^{-} \cdot+\mathrm{H}_{2} \mathrm{O} \rightarrow \mathrm{ClOH}^{-} \cdot+\mathrm{H}^{+}+\mathrm{Cl}^{-}$ & $k_{8}\left[\mathrm{H}_{2} \mathrm{O}\right]<1300 \pm 100 \mathrm{~s}^{-1}$ \\
\hline 9 & $\mathrm{Cl}_{2}^{-} \cdot+\mathrm{H}_{2} \mathrm{O}_{2} \rightarrow \mathrm{HO}_{2} \cdot+\mathrm{H}^{+}+2 \mathrm{Cl}^{-}$ & $k_{9}=(6.2 \pm 6.8) \times 10^{6} \mathrm{M}^{-1} \mathrm{~s}^{-1}$ \\
\hline 10 & $\mathrm{Cl} \cdot+\mathrm{H}_{2} \mathrm{O}_{2} \rightarrow \mathrm{H}^{+}+\mathrm{Cl}^{-}+\mathrm{HO}_{2}$ & $k_{10}=(2.0 \pm 0.3) \times 10^{9} \mathrm{M}^{-1} \mathrm{~s}^{-1}$ \\
\hline 11 & $\mathrm{Cl}_{2}^{-} \cdot+\mathrm{HO}_{2} \cdot \rightarrow \mathrm{O}_{2}+\mathrm{H}^{+}+2 \mathrm{Cl}^{-}$ & $k_{11}=(3.1 \pm 1.5) \times 10^{9} \mathrm{M}^{-1} \mathrm{~s}^{-1}$ \\
\hline 12 & $\mathrm{HO}_{2} \cdot+\mathrm{H}_{2} \mathrm{O}_{2} \rightarrow \mathrm{H}_{2} \mathrm{O}+\mathrm{O}_{2}+\mathrm{HO}$ & \\
\hline 13 & $\mathrm{HO} \cdot+\mathrm{HO} \cdot \rightarrow \mathrm{H}_{2} \mathrm{O}_{2}$ & \\
\hline 14 & $\mathrm{HO} \cdot+\mathrm{HO} \cdot \rightarrow \mathrm{H}_{2} \mathrm{O}+\mathrm{O} \cdot$ & - \\
\hline 15 & $\mathrm{HO}_{2} \cdot+\mathrm{HO}_{2} \cdot \rightarrow \mathrm{H}_{2} \mathrm{O}_{2}+\mathrm{O}_{2}$ & \\
\hline 16 & $\mathrm{HO} \cdot+\mathrm{HO}_{2} \cdot \rightarrow \mathrm{H}_{2} \mathrm{O}+\mathrm{O}_{2}$ & \\
\hline
\end{tabular}

${ }^{\text {a }}$ See Faust et al. ${ }^{79}$

${ }^{\mathrm{b}} \mathrm{See} \mathrm{Yu}$ and Barker.

$+\mathrm{Cl}^{-} \leftrightarrow \mathrm{Cl}_{2}^{-} \cdot$, has been the subject of several investigations. Literature values of $K_{5}$ near $20^{\circ} \mathrm{C}$ scattered over about 4 orders of magnitude. ${ }^{9-12}$ However, the recent values obtained by Buxton et al. ${ }^{12}$ and Yu and Barker ${ }^{6}$ agree reasonably well with that of Jayson et al. ${ }^{9}$ Recent works appear to have settled questions about the magnitude of this equilibrium constant $^{9-12}$ and led to a minor revision in the recommended values with improved uncertainty. Although the reaction between chlorine atoms and hydrogen peroxide is well known in the gas phase, ${ }^{13}$ it has only been determined in the aqueous phase recently. ${ }^{6} \mathrm{We}$ included this new measurement in Table 1 . The reaction $\mathrm{Cl} \cdot(\mathrm{aq})+\mathrm{Cl}_{2}^{-} \cdot(\mathrm{aq}) \rightarrow \mathrm{Cl}^{-}+\mathrm{Cl}_{2}$ was often missed in previous mechanisms. However, it plays an important role in the second-order decay of $\mathrm{Cl}_{2}^{-} \cdot(\mathrm{aq})$, therefore it is included in the mechanism.

In this paper, we evaluate rate constants and equilibrium constants determined in the previous two companion papers ${ }^{6,7}$ and present the most reliable values of either rate constants or equilibrium constants of aqueous phase free radical reactions involving $\mathrm{Cl} \cdot \mathrm{Cl}^{-}, \mathrm{Cl}_{2}^{-} \cdot \mathrm{HO} \cdot \mathrm{H}_{2} \mathrm{O}$, and $\mathrm{H}_{2} \mathrm{O}_{2}$ at room temperature. The tables in this paper include the published rate constants as presented in their original reports with some revisions where appropriate. The data included are published from the 1960s to January 2004. An update and critical evaluation of the recent and past works are necessary for experimentalists as well as modelers for future research in the $\mathrm{Cl}^{-} / \mathrm{H}_{2} \mathrm{O}_{2} / \mathrm{hv}$ aqueous system. Free radicals, such as $\mathrm{Cl} \cdot \mathrm{Cl}_{2}^{-} \cdot$, and $\mathrm{HOCl}^{-} \cdot$, are also basic chemical species in the study of electron transfer theory. The review of the kinetics study of the $\mathrm{Cl}^{-} / \mathrm{H}_{2} \mathrm{O}_{2} / \mathrm{hv}$ aqueous 
system provides an update of kinetics measurements as well as the source of a self-consistent set of thermodynamic data related to $\mathrm{Cl}$ - free radicals in the aqueous phase. ${ }^{14}$ Our main objectives of this paper are to provide insight into future research directions focused on halogen related free radical systems, specifically chlorine, and to provide a concise explanation and commentary of essential experimental kinetic approaches to solving complicated fast multiple equilibria problems.

\section{General Methods}

The dichlorine radical anions $\left(\mathrm{Cl}_{2}^{-} \cdot\right)$ were produced in most cases by pulse radiolysis of aqueous solutions. The radiolysis of water forms short-lived intermediates: hydrated electrons, hydrogen atoms, and hydroxyl radicals, which react rapidly with appropriate solute to yield the desired secondary radicals. ${ }^{3,4,15}$ In certain cases, these secondary radicals exhibit sufficient optical absorption in the visible or near-ultraviolet range that allows kinetic spectrophotometric measurements of the formation and decay rates. By following the decay rate as a function of added solute concentration one can determine the absolute second-order rate constant for the reaction of the radical with the added solute. In other cases, when the radical does not exhibit intense absorption, it is often possible to determine absolute rate constants by following the buildup of the species produced from the added solute upon reaction with the radical.

When none of these methods is applicable, the rate constants are determined by competition kinetics. In such cases, a reaction with a known absolute rate constant is chosen as a reference and the yield of the product of this reaction is determined as a function of the ratio of concentrations of the reference solute to other added solutes. From a plot of the yield ratios versus the concentration ratios, one derives the relative rate constants of the two competing reactions. Based on the known rate constant for the reference reaction, one then derives the rate constant for the unknown reaction. The competition method assumes constant radiation yield in all solutions examined and gives somewhat less precise results than the direct method. However, it is a useful strategy in many systems.

The results obtained from competition kinetics are not emphasized in this paper, because they intrinsically are affected by the relative rate constant depending on what reference solute is used. This evaluation focuses on rate constants and equilibrium constants obtained from direct methods. When a result obtained by competition kinetics is cited, the reference rate constant is not evaluated.

\section{Guide to the Data Sheets}

Some symbols appear repeatedly in the following discussions. A list of abbreviations and symbols used in the Data Sheets section is summarized here.

\begin{tabular}{|c|c|}
\hline$a$ & activity coefficient \\
\hline a & distance of closest approach between two ions \\
\hline ave. & average \\
\hline calc. & calculated \\
\hline$D$ & diameter \\
\hline$\varepsilon$ & molar extinction coefficient (base 10) \\
\hline$E_{a}$ & activation energy \\
\hline ESR & electron spin resonance \\
\hline EPR & electron paramagnetic resonance \\
\hline$\Phi$ & quantum yield \\
\hline Fenton & Fenton reaction \\
\hline FP & flash photolysis \\
\hline$\gamma-R$ & gamma radiolysis \\
\hline$G$ & $\begin{array}{l}\text { radiation yield (molecules per } 100 \mathrm{eV} \text { or } \\
\left.1.60209 \times 10^{-17} \mathrm{~J}\right)\end{array}$ \\
\hline$I$ & ionic strength \\
\hline$K$ & equilibrium constant \\
\hline$k$ & rate constant \\
\hline$k_{f}$ & the forward reaction rate constant \\
\hline$k_{\mathrm{obs}}$ & the observed rate constant \\
\hline$k_{r}$ & the reverse reaction rate constant \\
\hline$\lambda$ & wavelength $(\mathrm{nm})$ \\
\hline LFP & laser flash photolysis \\
\hline M & $\mathrm{mol} / \mathrm{L}$ \\
\hline N.A. & not available \\
\hline O.D. & optical density \\
\hline$p \mathrm{H}$ & $\begin{array}{l}\text { negative logarithm of the proton ions concentra- } \\
\text { tion, e.g., where } p \mathrm{H}=-\log \left(\left[\mathrm{H}^{+}\right]\right)\end{array}$ \\
\hline$p K_{a}$ & $\begin{array}{l}\text { negative logarithm of the acid dissociation con- } \\
\text { stant, e.g., where } \mathrm{AH}+\mathrm{H}_{2} \mathrm{O} \rightarrow \mathrm{A}^{-}+\mathrm{H}_{3} \mathrm{O}^{+}\end{array}$ \\
\hline PR & pulse radiolysis \\
\hline sim. & simulation \\
\hline$Z$ & ion charge \\
\hline
\end{tabular}

A list of chemical species appeared in the text is included in the following:

$\begin{array}{ll}\mathrm{t}-\mathrm{BuOH} & \text { tert-butyl alcohol (2-methyl-2-propanol) } \\ \mathrm{Cl} \cdot & \text { chlorine atom } \\ \mathrm{Cl}^{-} & \text {chloride ion } \\ \mathrm{Cl}_{2} & \text { chlorine molecule } \\ \mathrm{Cl}_{2}^{-} \cdot & \text { dichloride radical anion, dichlorine anion radical } \\ \mathrm{ClOH}^{-} \cdot & \text { ClOH minus radical } \\ \mathrm{EtOH}^{-} & \text {ethanol } \\ \mathrm{Fe}^{2+} & \mathrm{Fe}(\mathrm{II}) \text { ion } \\ \mathrm{HO} \cdot & \text { hydroxyl radical } \\ \mathrm{HO}_{2} \cdot & \text { hydroperoxyl radical } \\ \mathrm{H}_{2} \mathrm{O}_{2} & \text { hydrogen peroxide } \\ \mathrm{H}_{2} \mathrm{O} & \text { water } \\ \mathrm{MeOH}^{-} & \text {methanol } \\ \mathrm{RNO}^{-} & \text {N, N-dimethyl-4-nitrosoaniline } \\ \mathrm{SO}_{4}^{-} \cdot & \text { sulfate radical } \\ \mathrm{S}_{2} \mathrm{O}_{8}^{2-} & \text { persulfate ion }\end{array}$

The data discussed here are only for the photochemical kinetic information. 
TABLE 2. Rate constant data of $k_{2}$ by (a) direct measurements and (b) competition kinetics

\begin{tabular}{|c|c|c|c|c|c|c|c|}
\hline & \multicolumn{2}{|c|}{$k_{2} \times 10^{-7}\left(\mathrm{M}^{-1} \mathrm{~s}^{-1}\right)$} & Method & $p \mathrm{H}$ & \multicolumn{2}{|c|}{ Reference } & Notes \\
\hline \multirow[t]{6}{*}{ (a) } & & PR & N.A. & \multicolumn{2}{|c|}{$1962^{19}$} & $\mathrm{a}$ \\
\hline & & PR & 3 & & & $\mathrm{~b}$ \\
\hline & \multicolumn{2}{|c|}{$2.7 \pm 0.3$} & PR & $6.8-13.8$ & & & $\mathrm{c}$ \\
\hline & \multicolumn{2}{|c|}{2.7} & ave. & N.A. & & & $\mathrm{d}$ \\
\hline & \multicolumn{2}{|c|}{$4.2 \pm 0.2$} & LFP & 2 & & & $\mathrm{e}$ \\
\hline & $k_{2} \times 10^{-7}\left(\mathrm{M}^{-1} \mathrm{~s}^{-1}\right)$ & Method & \multicolumn{2}{|c|}{ Ratio } & $p \mathrm{H}$ & Reference & Notes \\
\hline \multirow[t]{9}{*}{ (b) } & 4.3 & FP & \multicolumn{2}{|c|}{$k_{\mathrm{HO} \cdot+\mathrm{Br}^{-}} / k_{2}=830$} & 2.2 & $1963^{24}$ & $\mathrm{a}$ \\
\hline & 2.25 & PR & \multicolumn{2}{|c|}{$k_{2} / k_{\mathrm{HO} \cdot+\mathrm{I}^{-}}=(2.2 \pm 0.7) \times 10^{-3}$} & 7 & $1965^{25}$ & $\mathrm{~b}$ \\
\hline & 8.8 & PR & \multicolumn{2}{|c|}{$k_{2} / k_{\mathrm{HO} \cdot+\mathrm{HCO}_{3}^{-}}=1.8$} & 8.4 & $1969^{26}$ & $\mathrm{c}$ \\
\hline & 5.9 & PR & \multicolumn{2}{|c|}{$k_{\mathrm{HO} \cdot+\text { thymine }} / k_{2}^{3}=72.4$} & 1.0 & $1969^{27}$ & $\mathrm{~d}$ \\
\hline & 1.7 & PR & \multicolumn{2}{|c|}{$k_{2} / k_{\mathrm{HO} \cdot+\mathrm{RNO}}=1.36 \times 10^{-2}$} & N.A. & $1969^{29}$ & $\mathrm{e}$ \\
\hline & 1.7 & $\mathrm{FP}$ & \multicolumn{2}{|c|}{$k_{2} / k_{\mathrm{HO} \cdot+\mathrm{RNO}}=1.36 \times 10^{-2}$} & 7 & $1974^{30}$ & $\mathrm{e}$ \\
\hline & 4.5 & $\gamma-\mathrm{R}$ & \multicolumn{2}{|c|}{$k_{2} / k_{\mathrm{HO} \cdot+\mathrm{RNO}}=3.6 \times 10^{-3}$} & $5-10.5$ & $1974^{31}$ & $\mathrm{e}$ \\
\hline & 3.8 & PR & \multicolumn{2}{|c|}{$k_{2} / k_{\mathrm{HO} \cdot+\text { Luminol }}=4.25 \times 10^{-3}$} & $7.7,9.3,11$ & $1980^{32}$ & $\mathrm{f}$ \\
\hline & 2.0 & $\mathrm{PR}$ & \multicolumn{2}{|c|}{$k_{\mathrm{HO} \cdot+\mathrm{SCN}^{-}} / k_{2}=550$} & 7 & $1981^{34}$ & $\mathrm{~g}$ \\
\hline
\end{tabular}

\subsection{Conventions Concerning Rate Constants}

All reactions listed in the tables are elementary processes. Thus, the rate expression is derived from a statement of the reaction, e.g.,

$$
\begin{gathered}
\mathrm{A}+\mathrm{A} \rightarrow \mathrm{B}+\mathrm{C} \\
-\frac{1}{2} \frac{\mathrm{d}[\mathrm{A}]}{\mathrm{d} t}=\frac{\mathrm{d}[\mathrm{B}]}{\mathrm{d} t}=\frac{\mathrm{d}[\mathrm{C}]}{\mathrm{d} t}=k[\mathrm{~A}]^{2}
\end{gathered}
$$

Note that the stoichiometric coefficient for A, i.e., 2, appears in the denominator before the rate of change of $[\mathrm{A}]$ (which is equal to $2 k[\mathrm{~A}]^{2}$; the square brackets [ ] represent concentration of the species) and as a power on the right hand side.

\subsection{Arrangement of Tables}

Tables 2-16 are arranged in the order of the occurrence of the reaction in Table 1 . The products of the reactions are included when they are known reasonably well or when they have been discussed in the paper reporting the data. In most cases, the rate constant listed is $k_{\text {obs }}$ at the quoted $p \mathrm{H}$. When ionic strength conditions were specified or could be derived from the description of the report, they are enclosed in the data sheet. In some case $k_{\mathrm{obs}}$ may be for a mixture of ionic forms of the substrate.

The method of radical generation is given by symbols such as PR (pulse radiolysis) and FP (flash photolysis), identified in the list of abbreviations and symbols. Other details of the determination and the system are described in the notes. Temperature and pressure are assumed to be ambient; otherwise the conditions will be noted. The references are followed at the end of the article.

\subsection{Data Evaluation}

Rate data selected for inclusion in this paper are based on the best available direct determination. Preference is given to data derived from pulse radiolysis, flash photolysis, or other kinetic or time-resolved methods capable of monitoring the formation or decay of the transient species $\mathrm{Cl}_{2}^{-} \cdot$. High priority is given to entries derived from publications containing the most comprehensive information concerning the experimental methodology, errors, conditions, details of parameters needed for the unambiguous identification and characterization of the reactive species, and the nature of the reaction, as well as factors influencing or controlling the reaction kinetics.

The uncertainties of the preferred values are assigned using the standard deviation of all reliable direct measurements. Therefore the uncertainties presented indicate the range of the available rate constant or equilibrium constant data. They are not determined by extensive statistical analysis of the data, which is often not allowed due to the limited data set or insufficient information.

\section{Data Sheets}

\section{1. $k_{2}, \mathrm{HO} \cdot+\mathrm{H}_{2} \mathrm{O}_{2} \rightarrow \mathrm{HO}_{2} \cdot+\mathrm{H}_{2} \mathrm{O}$.}

Both direct and indirect methods were used to measure $k_{2}$, which are discussed separately. The representative measurements of $p K_{a}$ of $\mathrm{HO} \cdot$ and $\mathrm{HO}_{2} \cdot$ are $11.9^{16,17}$ and $4.88,{ }^{18}$ respectively. The $k_{2}$ is not affected by the different $p \mathrm{H}$ environments reported.

\subsubsection{Direct Method}

Notes [Table 2(a)]

${ }^{\mathrm{a}}$ Schwarz $(1962),{ }^{19} k_{2}=4.5 \times 10^{7} \mathrm{M}^{-1} \mathrm{~s}^{-1}$.

The variation of $\mathrm{H}_{2} \mathrm{O}_{2}$ steady state was expressed as a function of pulse period. The mathematical derivation of $k_{2}$ is complicated. The $k_{2}$ was obtained by trial and error with one intermediate parameter until a consistent value was reached.

${ }^{\mathrm{b}}$ Fricke and Thomas $(1964),{ }^{20} k_{2}=1.2 \times 10^{7} \mathrm{M}^{-1} \mathrm{~s}^{-1}$.

Studies of reactions in solutions of $\mathrm{H}_{2} \mathrm{O}_{2}$ and $\mathrm{O}_{2}$ provided the absolute rate constants for a series of rate constants, one 
of which is $k_{2}$. With $G_{\mathrm{H}}=3.3, G_{\mathrm{HO}}=2.7, G_{\mathrm{H}_{2}}=0.45$, and $G_{\mathrm{H}_{2} \mathrm{O}_{2}}=0.75, k_{2}=1.2 \times 10^{7} \mathrm{M}^{-1} \mathrm{~s}^{-1}$ was obtained.

${ }^{2}$ Christensen et al. $\quad(1982),{ }^{21} \quad k_{2}=(2.7 \pm 0.3)$
$\times 10^{7} \mathrm{M}^{-1} \mathrm{~s}^{-1}$.

The value of $k_{2}$ was determined from the $p \mathrm{H}$ dependence of $k_{\text {obs }}$ which is a mixed rate constant involving reactions (2)-(5). The $k_{2}$ was derived by computer simulation of the following eight reactions that are involved with the observed $p \mathrm{H}$ dependence:

$$
\begin{gathered}
\mathrm{HO} \cdot+\mathrm{H}_{2} \mathrm{O}_{2} \rightarrow \mathrm{H}_{2} \mathrm{O}+\mathrm{O}_{2}^{-}+\mathrm{H}^{+} \\
\mathrm{O}^{-}+\mathrm{H}_{2} \mathrm{O}_{2} \rightarrow \mathrm{OH}^{-}+\mathrm{O}_{2}^{-}+\mathrm{H}^{+} \\
\mathrm{HO} \cdot+\mathrm{HO}_{2}^{-} \rightarrow \mathrm{OH}^{-}+\mathrm{O}_{2}^{-}+\mathrm{H}^{+} \\
\mathrm{O}^{-}+\mathrm{HO}_{2}^{-} \rightarrow \mathrm{OH}^{-}+\mathrm{O}_{2}^{-} \\
\mathrm{H}_{2} \mathrm{O}_{2}+\mathrm{OH}^{-} \rightarrow \mathrm{HO}_{2}^{-}+\mathrm{H}_{2} \mathrm{O} \\
\mathrm{HO}_{2}^{-}+\mathrm{H}_{2} \mathrm{O} \rightarrow \mathrm{H}_{2} \mathrm{O}_{2}+\mathrm{OH}^{-} \\
\mathrm{HO} \cdot+\mathrm{OH}^{-} \rightarrow \mathrm{O}^{-}+\mathrm{H}_{2} \mathrm{O} \\
\mathrm{O}^{-}+\mathrm{H}_{2} \mathrm{O} \rightarrow \mathrm{HO} \cdot+\mathrm{OH}^{-}
\end{gathered}
$$

The rate constant of reaction (3) was considered negligible, the rates of reactions (4) and (5) were known. ${ }^{22}$ The best fit was generated by using $k_{4}=(7.5 \pm 1.0) \times 10^{9} \mathrm{M}^{-1} \mathrm{~s}^{-1}$ and $k_{5}=(4.0 \pm 0.5) \times 10^{8} \mathrm{M}^{-1} \mathrm{~s}^{-1}$. Although the experimental technique is pulse radiolysis, $k_{2}$ was indeed determined by computer simulations.

${ }^{\mathrm{d}}$ Elliot and Buxton (1992), ${ }^{23} 2.7 \times 10^{7} \mathrm{M}^{-1} \mathrm{~s}^{-1}$.

This is a citation of the result of Christensen et $_{\text {al }}{ }^{21}$

${ }^{\mathrm{e}} \mathrm{Yu}$ and Barker (2003), ${ }^{6}(4.2 \pm 0.2) \times 10^{7} \mathrm{M}^{-1} \mathrm{~s}^{-1}$.

The rise and decay of $\mathrm{Cl}_{2}^{-}$. was analyzed. The rise rate constant of $\mathrm{Cl}_{2}^{-} \cdot$ could be expressed as $k_{A}=k_{2}\left[\mathrm{H}_{2} \mathrm{O}_{2}\right]$ $+k_{4} K_{3}\left[\mathrm{H}^{+}\right]\left[\mathrm{Cl}^{-}\right]$. The $k_{2}$ was directly obtained from the linear least squares analysis of $k_{A}$ versus $\left[\mathrm{H}_{2} \mathrm{O}_{2}\right]$. Whereas the $k_{4} K_{3}\left[\mathrm{H}^{+}\right]$was extracted from the subsequent linear least squares analysis of the intercept from the $k_{A}$ versus $\left[\mathrm{H}_{2} \mathrm{O}_{2}\right]$ analysis plotted as a function of $[\mathrm{NaCl}]$ under constant $p \mathrm{H}$ $2{ }^{6}$

\section{Preferred Values}

$$
k_{2}=(3.2 \pm 1.5) \times 10^{7} \mathrm{M}^{-1} \mathrm{~s}^{-1}
$$

\section{Comments on Preferred Values}

The preferred value of $k_{2}$ is the unweighted average of the four reported rate constants except Elliot and Buxton's ${ }^{23}$ result, because it is a citation of Christensen et $_{\text {al. }}{ }^{21}$

\subsubsection{Indirect Method}

The values of $k_{2}$ determined by competition kinetics methods are summarized below for completeness of comparison. No preferred value is concluded from the indirect measurement. Competition kinetics has been widely applied in determining $k_{2}$ using various scavengers. Relative rate ratios were obtained as a result. The accuracy of $k_{2}$ depends on the relative rate constant as explained in Sec. 1.

Notes [Table 2(b)] a Ferradini and Koulkès-Pujo (1963), ${ }^{24} k_{\mathrm{HO} \cdot+\mathrm{Br}^{-}} / k_{2}$ $=830$.

Bromide ions were used as the scavenger of hydroxyl radicals. The ratio $k_{\mathrm{HO} \cdot+\mathrm{Br}^{-}} / k_{2}=830$ was obtained. By using their value of $k_{\mathrm{HO} \cdot+\mathrm{Br}^{-}}=3.6 \times 10^{10} \mathrm{M}^{-1} \mathrm{~s}^{-1},{ }^{24} \quad k_{2}=4.3$ $\times 10^{7} \mathrm{M}^{-1} \mathrm{~s}^{-1}$ was determined.

${ }^{\mathrm{b}}$ Thomas $(1965),{ }^{25} k_{2} / k_{\mathrm{HO} \cdot+\mathrm{I}^{-}}=(2.2 \pm 0.7) \times 10^{-3}$.

The ratio $k_{2} / k_{\mathrm{HO} \cdot+\mathrm{I}^{-}}=(2.2 \pm 0.7) \times 10^{-3}$ was obtained by using iodide ions as the $\mathrm{HO} \cdot$ scavenger. With his own determination of $k_{\mathrm{HO} \cdot+\mathrm{I}^{-}}=(1.02 \pm 0.13) \times 10^{10} \mathrm{M}^{-1} \mathrm{~s}^{-1},{ }^{25} k_{2}$ $=2.25 \times 10^{7} \mathrm{M}^{-1} \mathrm{~s}^{-1}$ was derived.

${ }^{\mathrm{c}}$ Buxton (1961), ${ }^{26} k_{2} / k_{\mathrm{HO} \cdot+\mathrm{HCO}_{3}^{-}}=1.8$.

The ratio of $k_{2} / k_{\mathrm{HO} \cdot+\mathrm{HCO}_{3}^{-}}$was measured. The $k_{2}=8.8$ $\times 10^{7} \mathrm{M}^{-1} \mathrm{~s}^{-1}$ was determined by taking $k_{\mathrm{HO} \cdot+\mathrm{HCO}_{3}^{-}}=(4.9$ $\pm 0.5) \times 10^{7} \mathrm{M}^{-1} \mathrm{~s}^{-1} .^{26}$

${ }^{\mathrm{d}}$ Armstrong $(1961),{ }^{27} k_{\mathrm{HO} \cdot+\text { thymine }} / k_{2}=72.4$.

The $k_{2}$ was corrected first in this work by using a competition scheme involving $\mathrm{HO} \cdot$ and $\mathrm{H}_{2} \mathrm{O}_{2}$ and $\mathrm{HO} \cdot$ and thymine. The $k_{2}=5.9 \times 10^{7} \mathrm{M}^{-1} \mathrm{~s}^{-1}$ was determined by taking $k_{\mathrm{HO} \cdot+\text { thymine }}=(4.3 \pm 0.1) \times 10^{9} \mathrm{M}^{-1} \mathrm{~s}^{-1} \cdot{ }^{28}$

${ }_{\mathrm{e}}$ Baxendale and Khan $(1961),{ }^{29} k_{2} / k_{\mathrm{HO} \cdot+\mathrm{RNO}}=1.36$ $\times 10^{-2}$; Kachanova and Kozlov (1974), ${ }^{30} k_{2} / k_{\mathrm{HO} \cdot \mathrm{RNO}}$ $=1.36 \times 10^{-2} ;$ Hatada et al. (1974), ${ }^{31} k_{2} / k_{\mathrm{HO} \cdot+\mathrm{RNO}}=3.6$ $\times 10^{-3}$.

The above three used RNO ( $p$-nitrosodimethylaniline) as the competitor to study the $\mathrm{HO}$ radical reaction. Baxendale ${ }^{29}$ and Kachanova ${ }^{30}$ obtained almost identical ratio, whereas Hatada's ${ }^{31}$ result differs by almost a factor of 4 . It is unclear what causes the discrepancy.

$\mathrm{f}$ Merényi and Lind (1980), ${ }^{32} k_{2} / k_{\mathrm{HO} \cdot+\text { Luminol }}=4.25$ $\times 10^{-3}$.

Luminol was the scavenger of hydroxyl radicals. The ratio of $k_{2} / k_{\mathrm{HO} \cdot+\text { Luminol }}=4.25 \times 10^{-3}$ was measured. Taking previously determined $k_{\mathrm{HO} \cdot+\text { Luminol }}=8.7 \times 10^{9} \mathrm{M}^{-1} \mathrm{~s}^{-1},{ }^{33} k_{2}$ $=3.7 \times 10^{7} \mathrm{M}^{-1} \mathrm{~s}^{-1}$ was derived.

${ }^{\mathrm{g}}$ Greenstock and Wiebe (1981), ${ }^{34} k_{\mathrm{HO} \cdot+\mathrm{SCN}^{-}} / k_{2}=550$.

The $k_{2}=2.0 \times 10^{7} \mathrm{M}^{-1} \mathrm{~s}^{-1}$ was derived using the ratio $k_{\mathrm{HO} \cdot+\mathrm{SCN}^{-}} / k_{2}=550$ with $k_{\mathrm{HO} \cdot+\mathrm{SCN}^{-}}=1.1 \times 10^{10} \mathrm{M}^{-1} \mathrm{~s}^{-1} .{ }^{35}$

\section{Comments on Preferred Values}

No preferred value is given based upon results from indirect measurements.

\section{2. $k_{3}, \mathrm{HO} \cdot+\mathrm{Cl}^{-} \rightarrow \mathrm{ClOH}^{-}$.}

Similarly to $k_{2}, k_{3}$ have been determined both using direct and indirect methods. The following discussions of data are organized according to the determination method.

\subsubsection{Direct Method}

Notes [Table 3(a)]

${ }^{\mathrm{a}}$ Burton and Kurien (1959), ${ }^{36} k_{3}=4.0 \times 10^{9} \mathrm{M}^{-1} \mathrm{~s}^{-1}$.

The effect of halide ions in a system of hydrogen peroxide and halide ions was found to reduce $G_{\mathrm{H}_{2} \mathrm{O}_{2}}$. The plot of the fraction of free hydroxyl radicals unscavenged by halide ions versus a quantity, which is the product of the rate constant of the radical scavenging reaction, the concentration of the 
TABLE 3. Rate constant data of $k_{3}$ by (a) direct measurements and (b) competition kinetics

\begin{tabular}{|c|c|c|c|c|c|c|c|}
\hline \multirow[t]{5}{*}{ (a) } & \multicolumn{2}{|c|}{$k_{3} \times 10^{-9}\left(\mathrm{M}^{-1} \mathrm{~s}^{-1}\right)$} & \multicolumn{2}{|l|}{ Method } & \multicolumn{2}{|c|}{ Reference } & Notes \\
\hline & 4 & & $\gamma$-R & 2 & & & a \\
\hline & very & & $\gamma-\mathrm{R}$ & 10 & & & $\mathrm{~b}$ \\
\hline & $4.3 \pm$ & & PR & $\sim 2$ & & & $\mathrm{c}$ \\
\hline & $0.4-$ & & PR & N.A. & & & $\mathrm{d}$ \\
\hline \multirow[t]{10}{*}{ (b) } & $k_{3} \times 10^{-9}\left(\mathrm{M}^{-1} \mathrm{~s}^{-1}\right)$ & Method & & & $p \mathrm{H}$ & Reference & Notes \\
\hline & $0.089-0.64$ & PR & $k_{3} / k_{\mathrm{N}}$ & 715 & $1-2.5$ & $1964^{39}$ & a \\
\hline & $0.067-1.6$ & PR & $k_{3} / k_{\mathrm{Fe}(\mathrm{CN})}$ & -0.169 & $1-2.7$ & $1964^{39}$ & $\mathrm{a}$ \\
\hline & $<1.25 \times 10^{-3}$ & $\gamma-\mathrm{R}$ & & & 9 & $1965^{16}$ & $\mathrm{~b}$ \\
\hline & 0.52 & PR & & & 2 & $1967^{40}$ & $\mathrm{c}$ \\
\hline & 4.8 & PR & & & $\sim 0.1$ & $1967^{40}$ & $\mathrm{c}$ \\
\hline & 5.6 & $\gamma-\mathrm{R}$ & & & 1 & $1969^{27}$ & d \\
\hline & 0.035 & $\gamma-\mathrm{R}$ & & & 1.1 & $1969^{41}$ & e \\
\hline & 0.037 & $\gamma-\mathrm{R}$ & & & 1.1 & $1969^{41}$ & e \\
\hline & 1.32 & PLY & & & 1 & $1988^{42}$ & $\mathrm{f}$ \\
\hline
\end{tabular}

scavenger solute, and the defined initial time characteristic of the irradiation spur $\left(t_{\mathrm{o}}\right)$, followed the Ganguly-Magee relationship. With Ganguly and Magee $t_{\mathrm{o}}, k_{3}$ is determined as $4 \times 10^{9} \mathrm{M}^{-1} \mathrm{~s}^{-1}$.

${ }^{\mathrm{b}}$ Mattews and Sangster (1965), ${ }^{37}$ very low.

The $k_{3}$ was measured at very high $p \mathrm{H}$, i.e., alkaline conditions, which resulted in a very slow rate constant.

${ }^{\mathrm{c}}$ Jayson et al. (1973), ${ }^{9} k_{3}=(4.3 \pm 0.4) \times 10^{9} \mathrm{M}^{-1} \mathrm{~s}^{-1}$.

The observed rate constant of $\mathrm{Cl}_{2}^{-}$- rise, i.e., $\mathrm{HO} \cdot$ disappearance, was analyzed as a function of $\left[\mathrm{H}^{+}\right]$. Steady state approximations of $\mathrm{Cl} \cdot$, and $\mathrm{ClOH}^{-} \cdot$ were applied to derive the expression for the pseudo-first-order rate constant. Linear relationship was obtained: $\quad a_{\mathrm{Cl}^{-}} a_{\mathrm{H}^{+}} / k=\left(1 / k_{4} K_{3}\right)$ $+\left(a_{\mathrm{H}^{+}} / k_{3}\right)$. By plotting $a_{\mathrm{Cl}^{-}} a_{\mathrm{H}^{+}} / k$ versus $a_{\mathrm{H}^{+}}$, the data points yielded a straight line. The slope corresponded to $1 / k_{3}$, and the intercept $1 / k_{4} K_{3}$.

${ }^{\mathrm{d}}$ Grigorév et al. $(1987),{ }^{38} k_{3}=3.0 \times 10^{9} \mathrm{M}^{-1} \mathrm{~s}^{-1}$.

The results range from $(0.4-3.0) \times 10^{9} \mathrm{M}^{-1} \mathrm{~s}^{-1}$ with increasing $[\mathrm{NaCl}]$ and unspecified $p \mathrm{H}$. The details of their analysis were not given.

\section{Preferred Values}

$$
k_{3}=(4.2 \pm 0.2) \times 10^{9} \mathrm{M}^{-1} \mathrm{~s}^{-1} \text {. }
$$

\section{Comments on Preferred Values}

Mattews and Sangste's ${ }^{37}$ directly determined results were obtained under high $p \mathrm{H}$ conditions that is unfavorable for reactions (3) and (4) to proceed. Grigorév et al.'s results ${ }^{38}$ are not considered because they are in a wide range with no reported analytical details. Therefore the preferred value from directly determined measurements is obtained by the unweighted average of the reported values from Burton and Kurien $^{36}$ and Jayson et al. ${ }^{9}$

\subsubsection{Indirect Method}

Notes [Table 3(b)]

${ }^{\mathrm{a}}$ Anbar and Thomas (1964), ${ }^{39} k_{3} / k_{\mathrm{HO} \cdot+\mathrm{Fe}(\mathrm{CN})_{6}^{4-}=7.25}$ $\times 10^{-3}-0.169$ and $k_{3} / k_{\mathrm{HO} \cdot+\mathrm{MeOH}}=9.9-71.5 \times 10^{-2}$.

This is one of the earliest reports using competition kinetics to measure $k_{3}$. Both methanol and potassium ferrocya- nide were used under various $p \mathrm{H}$. The $k_{3}$ was found in a range of values depending on $\left[\mathrm{H}^{+}\right]$and $\left[\mathrm{Cl}^{-}\right]$.

${ }^{\mathrm{b}}$ Kraljíc and Trumbore $(1965),{ }^{16} k_{3} / k_{\mathrm{HO} \cdot+\mathrm{RNO}}=10^{-4}$.

The value of $k_{3}$ is very low under alkaline conditions.

${ }^{c}$ Kraljíc $(1967),{ }^{40} k_{3} / k_{\mathrm{HO} \cdot+\mathrm{RNO}}=4.2 \times 10^{-2},(p \mathrm{H}=2)$; $k_{3} / k_{\mathrm{HO} \cdot+\mathrm{RNO}}=0.381,(p \mathrm{H} \sim 0.1)$.

A series of scavengers such as $\mathrm{Br}^{-}, \mathrm{Cl}^{-}, \mathrm{RNO}, \mathrm{MeOH}$, $\mathrm{EtOH}$, and thymine was used to scavenge $\mathrm{HO}$.

${ }^{\mathrm{d}}$ Armstrong (1969), ${ }^{27} k_{3} / k_{\mathrm{HO} \cdot+\mathrm{H}_{2} \mathrm{O}_{2}}=9.5$.

A series of hydroxyl radical scavenger reactions was studied. The ratio of $k_{3} / k_{2}$ was obtained. There could be a typographical error in the ratio $k_{3} / k_{2}$ or $k_{3}$ in this paper. Since if we use the reported $k_{3} / k_{2}=9.5$ and $k_{2}=5.9$ $\times 10^{7} \mathrm{M}^{-1} \mathrm{~s}^{-1}, k_{3}=5.6 \times 10^{8} \mathrm{M}^{-1} \mathrm{~s}^{-1}$ is derived, which is different from what was reported in the paper, i.e., $k_{3}=5.6$ $\times 10^{9} \mathrm{M}^{-1} \mathrm{~s}^{-1}$. From the $k_{2}$ evaluation above, a ten times difference in $k_{2}$ is unreasonable. However, it is unclear whether $k_{3} / k_{2}$ or $k_{3}$ was reported with a mistake. In Table $3(\mathrm{~b})$, the value $5.6 \times 10^{9} \mathrm{M}^{-1} \mathrm{~s}^{-1}$ is listed, which is suspected to be the determined parameter.

${ }^{\mathrm{e}}$ Hughes and Makada (1969), ${ }^{41} k_{3} / k_{\mathrm{HO} \cdot \mathrm{MeOH}}=0.039$ and $k_{3} / k_{\mathrm{HO}+\mathrm{EeOH}}=0.020$.

Both methanol and ethanol were used to scavenge HOand ratios were obtained first. The ratio of $k_{\mathrm{HO} \cdot+\mathrm{MeOH}} / k_{3} / k_{\mathrm{HO} \cdot+\mathrm{EeOH}}=1.95$ was then derived. No $p \mathrm{H}$ dependence was mentioned. Hydrochloric acid was used to provide chloride ions. Their values are smaller than Anbar and Thomas' results. ${ }^{39}$ No explanation was given why a difference exists using methanol and ethanol as the $\mathrm{HO}$. scavenger. ${ }^{39,41}$

${ }^{\mathrm{f}}$ Pramanick et al. $(1988),{ }^{42} k_{3} / k_{\mathrm{HO} \cdot+\mathrm{M}}=1.11 \times 10^{-4}$.

The rate of $\mathrm{HO} \cdot$ reacting with halide ions was determined by entrapping the product radicals as polymer end groups that have been detected and estimated by a sensitive dye partition technique. The ratio of $k_{\mathrm{HO}+\mathrm{X}-}$ to $k_{\mathrm{M}}$ which is a predetermined rate constant of $\mathrm{HO} \cdot$ and a monomer, is equal to the ratio of the counts of halogen end group to that of the hydroxyl end group. Therefore, this method is essentially 
TABLE 4. Rate constant data of $k_{-3}$

\begin{tabular}{ccccccr}
\hline \hline$k_{3} \times 10^{-9}\left(\mathrm{M}^{-1} \mathrm{~s}^{-1}\right)$ & $k_{-3} \times 10^{-9}\left(\mathrm{~s}^{-1}\right)$ & $K_{3}\left(\mathrm{M}^{-1}\right)$ & Method & $p \mathrm{H}$ & Reference & Notes \\
\hline $4.3 \pm 0.4$ & $6.1 \pm 0.8$ & $0.70 \pm 0.13$ & PR & $<3$ & $1973^{9}$ & $\mathrm{a}$ \\
\hline
\end{tabular}

competition kinetics, because it relies upon the knowledge and accuracy of $k_{\mathrm{M}}$. The initiator efficiency is an important factor in the determination of $k_{3} .{ }^{43}$

\section{Comments on Preferred Values}

No preferred value is given based upon the results from indirect measurements.

\section{3. $K_{3}$ and $k_{-3}, \mathrm{ClOH}^{-} \cdot \rightarrow \mathrm{Cl}^{-}+\mathrm{HO}$.}

Notes (Table 4)

${ }^{a}$ Jayson et al. (1973), ${ }^{9} \quad K_{3}=0.7 \pm 0.13 \mathrm{M}^{-1} ; k_{3}=(4.3$ $\pm 0.4) \times 10^{9} \mathrm{M}^{-1} \mathrm{~s}^{-1} ; k_{3}=(6.1 \pm 0.8) \times 10^{9} \mathrm{~s}^{-1}$.

The most widely used value of $K_{3}$ is $0.70 \pm 0.13 \mathrm{M}^{-1} .{ }^{9}$ It was determined directly by using the linear relationship between the inverse of the difference of the optical density of $\mathrm{ClOH}^{-} \cdot$ and [HO-] in saturated nitrous oxide solution and saturated oxygen solution, respectively. The $k_{3}=(4.3 \pm 0.4)$ $\times 10^{9} \mathrm{M}^{-1} \mathrm{~s}^{-1}$ is the directly determined value, $k_{-3}=(6.1$ $\pm 0.8) \times 10^{9} \mathrm{~s}^{-1}$ was derived based on $K_{3}$ and $k_{3}$.

\section{Preferred Values}

$$
k_{-3}=(6.0 \pm 1.1) \times 10^{9} \mathrm{~s}^{-1} .
$$

\section{Comments on Preferred Values}

This is only report of $K_{3} \cdot{ }^{9}$ The preferred $k_{-3}$ is derived using the preferred value of $k_{3}$ and the only direct measurement of $K_{3}$. Since $k_{-3}$ is affiliated with $K_{3}$ and $k_{3}$, the recommended $k_{-3}$ is affected by $k_{3}$.

\section{4. $k_{4} K_{3}, \mathrm{HO} \cdot+\mathrm{Cl}^{-}+\mathrm{H}^{+} \rightarrow \mathrm{Cl} \cdot+\mathrm{H}_{2} \mathrm{O}$}

The global rate constant combining reactions (3) and (4), $k_{4} K_{3}$, was measured in many previous works. Using steady state approximation, the third-order global rate constant can be expressed as $k_{4} K_{3}$. The derivation and definition of the global rate constant are detailed elsewhere. ${ }^{6}$

Notes (Table 5)

a Anbar and Thomas (1964), ${ }^{39} \quad k_{4} K_{3}=1.16-2.16$ $\times 10^{10} \mathrm{M}^{-2} \mathrm{~s}^{-1} \quad(p \mathrm{H} \sim 3)$ and $0.32-1.84 \times 10^{10} \mathrm{M}^{-2} \mathrm{~s}^{-1}$ ( $p \mathrm{H} \mathrm{0-3)}$.

Anbar and Thomas measured the appearance of $\mathrm{Cl}_{2}^{-}$. Pseudo-first-order approximation was used to derive this rate constant. The concentration of solute $\left(\left[\mathrm{Cl}^{-}\right]\right)$was assumed to be unchanged during the pulse radiolysis process, i.e., $\mathrm{Cl}_{2}^{-}$- lifetime. The change of optical density, the difference between the optical density at time infinity, and that at any time $t$, was plotted as a function of time. The slope of such lines is the rate of the appearance of $\mathrm{Cl}_{2}^{-} \cdot$ A range of $k_{4} K_{3}$ was reported. Different ionic strength of the solution is considered to be the cause, since $k_{4}$ is affected by ionic strength.

${ }^{\mathrm{b}}$ Ward and Myers (1965), ${ }^{44} k_{4} K_{3}=7.6 \times 10^{9} \mathrm{M}^{-2} \mathrm{~s}^{-1}$.

The rate constant of $\mathrm{Cl}_{2}^{-}$. rise was measured. Both thymine and ethanol were used. Thymine was used as a measurable double-bonded component, and ethanol as a measurable saturated component. If both a double-bonded compound and a saturated compound are present in the aqueous solution, chlorine atoms will react specifically with the former, whereas hydroxyl free radicals will react with both. Oxygen removes hydrogen atoms, hydrated electrons, and organic radicals leaving $\mathrm{HO} \cdot$ and $\mathrm{Cl} \cdot$ the only effective attacking species. The relative rate constant ratios of $\mathrm{HO} \cdot$ and ethanol or HO$\cdot$ and thymine were determined. $G_{- \text {thymine }}$ varied with $p \mathrm{H}$ and $\left[\mathrm{Cl}^{-}\right]$. However, the ratio $k_{\mathrm{HO} \cdot+\text { thymine }} / k_{\mathrm{HO} \cdot+\text { ethanol }}$ remained constant. Their results showed that as $p \mathrm{H}$ increased the $\mathrm{Cl}$ - involvement in the reactions decreased in aqueous solutions containing thymine and ethanol. Chloride concentration and $p \mathrm{H}$ of solutions were kept constant in their experiments. The ratio of $k_{\mathrm{HO} \cdot+\text { thymine }} / k_{\mathrm{HO}++ \text { ethanol }}$ was useful in determining $G_{\mathrm{Cl}^{-}+\mathrm{H}^{+}+\mathrm{HO}} \cdot / G_{\text {thymine }+\mathrm{HO}}$. The plot of $G_{\mathrm{Cl}^{-}+\mathrm{H}^{+}+\mathrm{HO}} / G_{\text {thymine }+\mathrm{HO}}$. versus $\left[\mathrm{H}^{+}\right] \cdot\left[\mathrm{Cl}^{-}\right]$was fitted with a linear relationship. The slope of such line is $k_{\mathrm{Cl}^{-}+\mathrm{H}^{+}+\mathrm{HO}} . / k_{\text {thymine }+\mathrm{HO}}=1.9 \pm 0.3 \mathrm{M}^{-1}$. The $k_{4} K_{3}=7.6$ $\times 10^{9} \mathrm{M}^{-2} \mathrm{~s}^{-1}$ was derived by using $k_{\text {thymine }+\mathrm{HO}}=4$ $\times 10^{9} \mathrm{M}^{-1} \mathrm{~s}^{-1}{ }^{45}$

${ }^{\mathrm{c}}$ Ward and Kuo (1968), ${ }^{44} k_{4} K_{3}=1.5 \times 10^{10} \mathrm{M}^{-2} \mathrm{~s}^{-1}$.

Ward and Kuo found that $k_{4} K_{3}$ showed a first-order dependence on $\left[\mathrm{H}^{+}\right]$and $\left[\mathrm{Cl}^{-}\right]$. A published relative rate constant was used to obtain $k_{4} K_{3}=1.5 \times 10^{10} \mathrm{M}^{-2} \mathrm{~s}^{-1}$. However, the specific relative reaction and its rate constant were not specified. Since Ward ${ }^{46}$ used thymine and $\mathrm{HO}$ reaction previously as the reference reaction, it is assumed that they used the same relative reaction again in this slightly later work. By using the same referenced value of the relative

TABLE 5. Rate constant data of $k_{4} K_{3}$ by direct and competition kinetics

\begin{tabular}{|c|c|c|c|c|c|c|}
\hline$k_{4} K_{3} \times 10^{-10}\left(\mathrm{M}^{-2} \mathrm{~s}^{-1}\right)$ & Method & Ratio & $I(\mathrm{M})$ & $p \mathrm{H}$ & Reference & Notes \\
\hline $1.16-2.16$ & PR & $\ldots$ & $<0.15$ & $1-3$ & $1964^{39}$ & $\mathrm{a}$ \\
\hline $0.32-1.84$ & PR & $\ldots$ & $1\left(\mathrm{NaClO}_{4}\right)$ & $0-3$ & $1964^{39}$ & $\mathrm{a}$ \\
\hline 0.76 & $\gamma-\mathrm{R}$ & $k_{4} K_{3} / k_{\text {thymine }}=1.9 \mathrm{M}^{-1}$ & $<0.2$ & $\sim 1-3$ & $1965^{46}$ & $\mathrm{~b}$ \\
\hline 1.5 & PR & $k_{4} K_{3} / k_{\text {thymine }}=3.75 \mathrm{M}^{-1}$ & $<0.2$ & $0.8-3.4$ & $1968^{44}$ & $\mathrm{c}$ \\
\hline $1.5 \pm 0.12$ & PR & 等 & $<0.1$ & 3 & $1973^{9}$ & $\mathrm{~d}$ \\
\hline 1.85 or 1.9 & PR & $\ldots$ & $0.05 / 0.06$ & 2 & $1973^{47}$ & $\mathrm{e}$ \\
\hline $1.8 \pm 0.1$ & FP & $\cdots$ & $\sim 0.01$ & 2 & $2003^{6}$ & $\mathrm{f}$ \\
\hline
\end{tabular}


TABLE 6. Data of $K_{4}$ and $k_{4}$

\begin{tabular}{|c|c|c|c|c|c|c|}
\hline$k_{-4}\left[\mathrm{H}_{2} \mathrm{O}\right] \times 10^{-5}\left(\mathrm{~s}^{-1}\right)$ & $k_{4} \times 10^{-10}\left(\mathrm{M}^{-1} \mathrm{~s}^{-1}\right)$ & $K_{4}\left(\times 10^{-6}\right)$ & Method & $p \mathrm{H}$ & Reference & Notes \\
\hline $0.17-1.7$ & $2.1 \pm 0.7$ & 9-44 & PR & $<3$ & $1973^{9}$ & $\mathrm{a}$ \\
\hline $2.0 \pm 0.2$ & $2.6 \pm 0.6$ & $7.2 \pm 1.6$ & FP & 2 & $2003^{6}$ & $\mathrm{~b}$ \\
\hline
\end{tabular}

reaction rate constant, a ratio of $k_{\mathrm{Cl}^{-}+\mathrm{H}^{+}+\mathrm{HO}} / k_{\text {thymine }+\mathrm{HO}}$. $=3.75 \mathrm{M}^{-1}$ was derived.

${ }^{\mathrm{d}}$ Jayson et al. (1973), ${ }^{9} k_{4} K_{3}=1.5 \times 10^{10} \mathrm{M}^{-2} \mathrm{~s}^{-1}$.

The method of how Jayson et al. obtained $k_{4} K_{3}$ has been described in the section of $k_{3}$ evaluation. Essentially, the rate constant of $\mathrm{Cl}_{2}^{-}$appearance is expressed as a function of both $\left[\mathrm{H}^{+}\right]$and $\left[\mathrm{Cl}^{-}\right]$.

e Ogura and Hamill (1973), ${ }^{47} k_{4} K_{3}=1.85$ or 1.9 $\times 10^{10} \mathrm{M}^{-2} \mathrm{~s}^{-1}$.

Ogura and Hamill used the same strategy as Anbar and Thomas. ${ }^{39}$ The change of optical density was plotted against time. The slope of such lines corresponds to the rate constant of $\mathrm{Cl}_{2}^{-}$appearance in either $\mathrm{H}_{2} \mathrm{O}$ or $\mathrm{D}_{2} \mathrm{O}$.

$\mathrm{f} Y$ Yu and Barker $\quad(2003),{ }^{6} \quad k_{4} K_{3}=(1.8 \pm 0.1)$
$\times 10^{10} \mathrm{M}^{-2} \mathrm{~s}^{-1}$

The rise and decay of $\mathrm{Cl}_{2}^{-}$. was analyzed. The global rate constant $k_{4} K_{3}\left[\mathrm{H}^{+}\right]$was derived using steady state approximation. More details are seen in Sec. 4.1.1.

\section{Preferred Values}

$k_{4} K_{3}=(1.7 \pm 0.3) \times 10^{10} \mathrm{M}^{-2} \mathrm{~s}^{-1}$.

\section{Comments on Preferred Values}

The preferred value is the unweighted average of the reported global rate constants except the result by Ward and Myers, ${ }^{44}$ because it is suspected that there is a typographical error in their reported value.

\section{5. $K_{4}$ and $k_{4}, \mathrm{ClOH}^{-} \cdot+\mathrm{H}^{+} \rightarrow \mathrm{Cl} \cdot+\mathrm{H}_{2} \mathrm{O}$}

Notes (Table 6)

${ }^{\mathrm{a}}$ Jayson et al. $(1973),{ }^{9} k_{4}=(2.1 \pm 0.7) \times 10^{10} \mathrm{M}^{-1} \mathrm{~s}^{-1}$.

Jayson et al. defined a standard absorbance of $\mathrm{Cl}_{2}^{-} \cdot$ at $\left[\mathrm{Cl}^{-}\right]=0.01 \mathrm{M}$ and $\left[\mathrm{H}^{+}\right]=0.01 \mathrm{M}$. Then various absorbencies of $\mathrm{Cl}_{2}^{-}$at different $\left[\mathrm{Cl}^{-}\right]$and $\left[\mathrm{H}^{+}\right]$conditions were compared with the standard absorbance. The ratio was expressed as a function of both $K_{3} K_{4}$ and $K_{5}$, which were solved for their most probable values. The preferred solutions of $K_{3} K_{4}$ and $K_{5}$ are $1.1 \times 10^{7}$ and $1.9 \times 10^{5} \mathrm{M}^{-1}$ from a range of $7.5 \times 10^{6} \mathrm{M}^{-1}-2.5 \times 10^{7} \mathrm{M}^{-1}$, and 1.4 $\times 10^{5}-2.8 \times 10^{5}$, respectively. Then $K_{3}$ was determined directly by plotting the difference of optical density (O.D.) versus $a_{\mathrm{Cl}^{-}}$following this relationship:

$$
\frac{1}{\text { O.D. }}=\frac{1}{5} K_{3} \cdot a_{\mathrm{Cl}} \cdot[\mathrm{HO} \cdot]_{\mathrm{o}} \cdot \varepsilon_{\mathrm{Cl}_{2}^{-}}+\frac{1}{5}[\mathrm{HO} \cdot]_{\mathrm{o}} \cdot \varepsilon_{\mathrm{Cl}_{2}^{-}}
$$

where the factor of 5 comes from the optical path length, and $[\mathrm{HO} \cdot]_{\mathrm{o}}$ is the hydroxyl radical concentration introduced by reaction of the hydrated electron with nitrous oxide with a yield $G=2.75$. The value of $K_{4}$ could then be derived as $1.6 \times 10^{7} \mathrm{M}^{-1}$. The derivation of $k_{4}$ was not specified, however, since it has almost the identical numerical value as that of $k_{5}$, i.e., $2.1 \times 10^{10} \mathrm{M}^{-1} \mathrm{~s}^{-1}$, it is suspected that it was obtained by following the same diffusion controlled calculation. It is unclear why $k_{4}$ has a $30 \%$ error, whereas $k_{5}$ does not.

${ }^{\mathrm{b}} \mathrm{Yu}$ and Barker $(2003),{ }^{6} k_{4}=(2.6 \pm 0.6) \times 10^{10} \mathrm{M}^{-1} \mathrm{~s}^{-1}$.

The $k_{4} K_{3}=1.8 \times 10^{10} \mathrm{M}^{-2} \mathrm{~s}^{-1}$ was directly determined (seen in Sec. 4.4.1), and $k_{4}=2.6 \times 10^{10} \mathrm{M}^{-1} \mathrm{~s}^{-1}$ was derived using $K_{3}=0.70 \pm 0.13 \mathrm{M}^{-1}$ by Jayson et al. ${ }^{9}$ The $K_{4}$ was thereby $(7.2 \pm 1.6) \times 10^{6}$ based on $k_{-4}\left[\mathrm{H}_{2} \mathrm{O}\right]=(2.0 \pm 0.2)$ $\times 10^{5} \mathrm{~s}^{-1}$

\section{Preferred Values \\ $k_{4}=(2.4 \pm 0.4) \times 10^{10} \mathrm{M}^{-1} \mathrm{~s}^{-1}$. \\ $K_{4}=(7.4 \pm 2.8) \times 10^{6}$.}

\section{Comments on Preferred Values}

The preferred $k_{4}$ is the unweighted average of the two reported values. The difference in $K_{4}$ is caused by $k_{4}$, since the same $K_{3}$ was used to derive $k_{4}$ from $k_{4} K_{3}$. The preferred value of $K_{4}$ is determined once $k_{-4}$ is evaluated.

\section{6. $k_{-4}\left[\mathrm{H}_{2} \mathrm{O}\right], \mathrm{Cl} \cdot+\mathrm{H}_{2} \mathrm{O} \rightarrow \mathrm{ClOH}^{-} \cdot+\mathrm{H}^{+}$}

The $k_{-4}$ is commonly reported as $k_{-4}\left[\mathrm{H}_{2} \mathrm{O}\right]$ in the literature. In order to avoid confusion, we compare $k_{-4}\left[\mathrm{H}_{2} \mathrm{O}\right]$ here. Essentially, we should compare the ratio of $k_{-4}\left[\mathrm{H}_{2} \mathrm{O}\right] / K_{5}$ instead of $k_{-4}\left[\mathrm{H}_{2} \mathrm{O}\right]$, because the latter is affected by the $K_{5}$ value taken by different researchers. Although Jayson et al.'s ${ }^{9} K_{5}$ has been widely used in the derivation of other rate constants, it is not necessarily the most accurate measurement. The uncertainty of $K_{5}$ reported in the original paper is quite high, i.e., $(1.4-2.8) \times 10^{5} \mathrm{M}^{-1}$. More discussion on $K_{5}$ is detailed in the following section. When justification is necessary, a $10 \%$ error is arbitrarily assigned to $K_{5}$. For convenience of comparison, the $K_{5}$ used to calculate $k_{-4}\left[\mathrm{H}_{2} \mathrm{O}\right] / K_{5}$ is listed in a separate column.

Notes (Table 7)

a Jayson et al. (1973), ${ }^{9} k_{-4}\left[\mathrm{H}_{2} \mathrm{O}\right]=7.2 \times 10^{4} \mathrm{~s}^{-1}$.

The description of how Jayson et al. obtained $k_{4}$ and $K_{4}$ is in Sec. 4.5. The value of $k_{-4}$ was derived based on $k_{4}$ and $K_{4}$. Since the equilibrium constant $K_{4}$ was in a range $(0.9-4.4) \times 10^{7}$ and $k_{4}=(2.1 \pm 0.7) \times 10^{10} \mathrm{M}^{-1} \mathrm{~s}^{-1}$, the $k_{-4}\left[\mathrm{H}_{2} \mathrm{O}\right]$ obtained falls in a range: (0.3-3.0) $\times 10^{3} \mathrm{M}^{-1} \mathrm{~s}^{-1}$.

${ }^{\mathrm{b}}$ Kläning and Wolff $(1985),{ }^{48} k_{-4}\left[\mathrm{H}_{2} \mathrm{O}\right]=1.6 \times 10^{5} \mathrm{~s}^{-1}$.

As noted in their paper, $K_{5}=1.9 \times 10^{5} \mathrm{M}^{-1}$ was used. It is postulated that $k_{-4}\left[\mathrm{H}_{2} \mathrm{O}\right] / K_{5}$ was the quantity that was measured in their experiment. However, the details of analytical method were not described.

${ }^{\mathrm{c}}$ Wine et al. (1988), $k_{-4}\left[\mathrm{H}_{2} \mathrm{O}\right]=1 \times 10^{5} \mathrm{~s}^{-1}$.

The detail of this result is not available. This is a conference presentation. 
TABLE 7. Rate constant data of $k_{-4}\left[\mathrm{H}_{2} \mathrm{O}\right]$

\begin{tabular}{|c|c|c|c|c|c|c|}
\hline$k_{-4}\left[\mathrm{H}_{2} \mathrm{O}\right] \times 10^{-5}\left(\mathrm{~s}^{-1}\right)$ & $k_{-4}\left[\mathrm{H}_{2} \mathrm{O}\right] / K_{5}\left(\mathrm{M} \mathrm{s}^{-1}\right)$ & $K_{5} \times 10^{-5}\left(\mathrm{M}^{-1}\right)$ & Method & $p \mathrm{H}$ & Reference & Notes \\
\hline $0.17-1.7$ & & $1.4-2.8$ & PR & $<3$ & $1973^{9}$ & $\mathrm{a}$ \\
\hline 1.6 & 0.84 & 1.9 & N.A. & $>11$ & $1985^{48}$ & $\mathrm{~b}$ \\
\hline 1.0 & & 1.9 & FP & & 1988 & $\mathrm{c}$ \\
\hline $2.5 \pm 0.2$ & $1.3 \pm 0.2$ & 1.9 & PR & $2-4$ & $1990^{49}$ & $\mathrm{~d}$ \\
\hline $2.3 \pm 0.6$ & $1.2 \pm 0.3$ & 1.9 & FP & 4 & $1997^{50}$ & $\mathrm{e}$ \\
\hline $2.5 \pm 0.3$ & $1.8 \pm 0.6$ & $1.4 \pm 0.1$ & PR & $5-6$ & $1998^{12}$ & $\mathrm{f}$ \\
\hline $2.0 \pm 0.2$ & $1.4 \pm 0.1$ & $1.4 \pm 0.2$ & FP & 2 & $2003^{6}$ & $\mathrm{~g}$ \\
\hline $1.6 \pm 0.2$ & $1.1 \pm 0.1$ & $1.4 \pm 0.2$ & FP & 2 & $2004^{8}$ & $\mathrm{~h}$ \\
\hline
\end{tabular}

${ }^{\mathrm{d}}$ McElroy $(1990),{ }^{49} k_{-4}\left[\mathrm{H}_{2} \mathrm{O}\right]=(2.5 \pm 0.2) \times 10^{5} \mathrm{~s}^{-1}$.

Although a different form of $k_{-4}\left[\mathrm{H}_{2} \mathrm{O}\right]$ expression was used in McElroy's analysis, the essence of the mathematical relationship is the same as the above works. With the measured $k_{-4}\left[\mathrm{H}_{2} \mathrm{O}\right]=(1.3 \pm 0.1) \times 10^{3} \mathrm{~s}^{-1}$ from the same work and Jayson et al.'s $K_{5}$, the most reliable estimate of $k_{-4}\left[\mathrm{H}_{2} \mathrm{O}\right]$ was $(2.5 \pm 0.2) \times 10^{5} \mathrm{~s}^{-1}$ at $\left[\mathrm{Cl}^{-}\right]=10^{-3} \mathrm{M}$. In order to make the error propagation of $k_{-4}\left[\mathrm{H}_{2} \mathrm{O}\right] / K_{5}$ meaningful, it is assumed that the error of $K_{5}$ is $10 \%$. The justified ratio of $k_{-4}\left[\mathrm{H}_{2} \mathrm{O}\right] / K_{5}$ is therefore $1.3 \pm 0.2 \mathrm{M} \mathrm{s}^{-1}$ from McElroy's original data.

${ }^{\text {e }}$ Jacobi et al. (1997), ${ }^{50} \quad k_{-4}\left[\mathrm{H}_{2} \mathrm{O}\right]=(2.3 \pm 0.6)$ $\times 10^{5} \mathrm{~s}^{-1}$.

The ratio of $k_{-4}\left[\mathrm{H}_{2} \mathrm{O}\right] / K_{5}=1.2 \pm 0.3 \mathrm{M} \mathrm{s}^{-1}$ was obtained from the linear least squares fit of the observed first-order decay rate constant of $\mathrm{Cl}_{2}^{-} \cdot$ versus $1 /\left[\mathrm{Cl}^{-}\right]$. By taking Jayson et al.'s equilibrium constant, ${ }^{9} \quad K_{5}=1.9 \times 10^{5} \mathrm{M}^{-1}$, $k_{-4}\left[\mathrm{H}_{2} \mathrm{O}\right]$ was derived.

$$
\mathrm{f} \text { Buxton et al. (1998), }{ }^{12} \quad k_{-4}\left[\mathrm{H}_{2} \mathrm{O}\right]=(2.5 \pm 0.3)
$$$$
\times 10^{5} \mathrm{~s}^{-1} \text {. }
$$

Buxton et al. obtained $k_{-4}\left[\mathrm{H}_{2} \mathrm{O}\right] / k_{-5}$ in their analysis. With their $k_{5}=(8.5 \pm 0.7) \times 10^{9} \mathrm{M}^{-1} \mathrm{~s}^{-1}$ and $K_{5}=k_{5} / k_{-5}$, $k_{-4}\left[\mathrm{H}_{2} \mathrm{O}\right] / K_{5}$ was calculated with propagated uncertainty. Using $K_{5}=1.4 \times 10^{5} \mathrm{M}^{-1}$ determined in the same study, $k_{-4}\left[\mathrm{H}_{2} \mathrm{O}\right]$ was derived.

${ }_{\mathrm{g}} \mathrm{Yu}$ and Barker (2003), ${ }^{6} \quad k_{-4}\left[\mathrm{H}_{2} \mathrm{O}\right]=(2.0 \pm 0.2)$ $\times 10^{5} \mathrm{~s}^{-1}$.

The rise and decay of $\mathrm{Cl}_{2}^{-} \cdot$ was analyzed and the rise and decay rate constants of $\mathrm{Cl}_{2}^{-}$. were obtained. The $k_{-4}\left[\mathrm{H}_{2} \mathrm{O}\right] / K_{5}$ was extracted by linear least squares fitting of the intercept data from the linear least squares fits of the decay rate constant of $\mathrm{Cl}_{2}^{-}$. as a function of $\left[\mathrm{H}_{2} \mathrm{O}_{2}\right]$. This is essentially the same approach as Jacobi et al. ${ }^{50}$ With the recommended $K_{5}=(1.4 \pm 0.2) \times 10^{5} \mathrm{M}^{-1}$ (discussion in Sec. 4.7), $k_{-4}\left[\mathrm{H}_{2} \mathrm{O}\right]$ was derived.

${ }^{\mathrm{h}} \mathrm{Yu}$ et al. $(2004),{ }^{8} k_{-4}\left[\mathrm{H}_{2} \mathrm{O}\right]=(1.6 \pm 0.2) \times 10^{5} \mathrm{~s}^{-1}$.

Similar to $\mathrm{Yu}$ and Barker's previous work, the $k_{-4}\left[\mathrm{H}_{2} \mathrm{O}\right] / K_{5}$ was extracted by linear least squares fitting of the intercept data from the linear least squares fits of the decay rate constant of $\mathrm{Cl}_{2}^{-} \cdot$ as a function of $\left[\mathrm{S}_{2} \mathrm{O}_{8}^{2-}\right]$. With $K_{5}=(1.4 \pm 0.2) \times 10^{5} \mathrm{M}^{-1}, k_{-4}\left[\mathrm{H}_{2} \mathrm{O}\right]$ was derived.

\section{Preferred Values}

$$
\begin{aligned}
& k_{-4}\left[\mathrm{H}_{2} \mathrm{O}\right] / K_{5}=1.3 \pm 0.3 \mathrm{M} \mathrm{s}^{-1} . \\
& k_{-4}\left[\mathrm{H}_{2} \mathrm{O}\right]=(1.8 \pm 0.6) \times 10^{5} \mathrm{~s}^{-1} . \\
& K_{4}=(7.4 \pm 2.8) \times 10^{6} .
\end{aligned}
$$

\section{Comments on Preferred Values}

The preferred ratio $k_{-4}\left[\mathrm{H}_{2} \mathrm{O}\right] / K_{5}$ was evaluated first by using the unweighted average of the available values. The preferred $k_{4}\left[\mathrm{H}_{2} \mathrm{O}\right]$ was given based upon the recommended value of $K_{5}=(1.4 \pm 0.2) \times 10^{5} \mathrm{M}^{-1}$. The preferred value of $K_{4}$ was derived based on the preferred $k_{4}$ and $k_{-4}\left[\mathrm{H}_{2} \mathrm{O}\right]$ using $K_{4}=k_{4} / k_{-4}$.

\section{7. $k_{5}, k_{-5}$, and $K_{5}, \mathrm{Cl} \cdot+\mathrm{Cl}^{-} \leftrightarrow \mathrm{Cl}_{2}^{-}$. 4.7.1. Forward Rate Constant $k_{5}$}

The value of $k_{5}$ has been determined in several previous studies. ${ }^{9,12,48,51-53}$

Notes (Table 8)

a Jayson et al. (1973), ${ }^{9} k_{5}=2.1 \times 10^{10} \mathrm{M}^{-1} \mathrm{~s}^{-1}$ and 4.1 $\times 10^{9} \mathrm{M}^{-1} \mathrm{~s}^{-1}$.

The $k_{5}=2.1 \times 10^{10} \mathrm{M}^{-1} \mathrm{~s}^{-1}$ was not determined experi-

\begin{tabular}{|c|c|c|c|c|c|c|}
\hline$k_{5} \times 10^{-9}\left(\mathrm{M}^{-1} \mathrm{~s}^{-1}\right)$ & Method & $\begin{array}{c}\text { Photolysis } \\
\lambda(\mathrm{nm})\end{array}$ & $\begin{array}{c}\text { Probe } \\
\lambda(\mathrm{nm})\end{array}$ & $p \mathrm{H}$ & Reference & Notes \\
\hline 4.1 & PR & N.A. & 340 & 0 & $1973^{9}$ & $\mathrm{a}$ \\
\hline 21 & estimated & - & 340 & 0 & $1973^{9}$ & $\mathrm{a}$ \\
\hline $6.5 \pm 0.9$ & LFP & 308 & 360 & 10.0 & $1985^{48}$ & $\mathrm{~b}$ \\
\hline $8.0 \pm 0.8$ & LFP & 248 & 340 & $\sim 3.5$ & $1985^{51}$ & $\mathrm{c}$ \\
\hline 8 & LFP & N.A. & 340 & $<5.5$ & $1986^{52}$ & $\mathrm{~d}$ \\
\hline 19.2 & LFP & 193 & 340 & N.A. & $1993^{53}$ & e \\
\hline $8.5 \pm 0.7$ & LFP & 193 & 340 & N.A. & $1998^{12}$ & $\mathrm{f}$ \\
\hline $7.8 \pm 0.8$ & ave. & - & - & - & $2003^{6}$ & $\mathrm{~g}$ \\
\hline
\end{tabular}
mentally; instead it was calculated by assuming diffusion control. In fact, they reported a single measured pseudo-first-

TABLE 8 . Rate constant data of $k_{5}$ by direct measurements 
order rate constant of $4.1 \times 10^{6} \mathrm{~s}^{-1}$ when the concentrations of hydrogen ions and chloride ions were 1 and $10^{-3} \mathrm{M}$, respectively. ${ }^{9}$ The corresponding value for $k_{5}=4.1$ $\times 10^{9} \mathrm{M}^{-1} \mathrm{~s}^{-1}$ is only $\sim 20 \%$ of the diffusion limit. No explanation was given why the assumed diffusion controlled rate constant was preferred to their experimental value.

${ }^{\mathrm{b}}$ Kläning and Wolff $(1985),{ }^{48} k_{5}=6.5 \times 10^{9} \mathrm{M}^{-1} \mathrm{~s}^{-1}$.

The $k_{5}$ was directly measured by generating $\mathrm{Cl}_{2}^{-} \cdot$ by laser flash photolysis of $\mathrm{ClO}^{-}$and $\mathrm{Cl}^{-}$under alkaline conditions at $308 \mathrm{~nm}$, and monitoring the optical density of $\mathrm{Cl}_{2}^{-} \cdot$ at 360 $\mathrm{nm}$. Under their conditions, the formation of $\mathrm{Cl}_{2}^{-} \cdot$ is in competition with several other reactions. From a least squares analysis of their data, $k_{5}$ was determined with no reported uncertainty.

${ }^{c}$ Nagaranjan and Fessenden (1985), ${ }^{51} k_{5}=(8.0 \pm 0.8)$ $\times 10^{9} \mathrm{M}^{-1} \mathrm{~s}^{-1}$.

Nagaranjan and Fessenden ${ }^{51}$ generated $\mathrm{Cl}_{2}^{-} \cdot$ by laser flash photolysis of aqueous $\mathrm{Cl}^{-}$and $\mathrm{S}_{2} \mathrm{O}_{8}^{2-}$ at $248 \mathrm{~nm}$ and then used a subsequent photolysis pulse at $355 \mathrm{~nm}$ or $337 \mathrm{~nm}$ to photodissociate $\mathrm{Cl}_{2}^{-} \cdot$. The dissociation of the $\mathrm{Cl}_{2}^{-} \cdot$ (monitored at $340 \mathrm{~nm}$ ) results in a "bleach" and a subsequent exponential recovery back to the original absorption level. The plot of the recovery rate of $\mathrm{Cl}_{2}^{-} \cdot$ versus $\left[\mathrm{Cl}^{-}\right]$was analyzed by least squares analysis to determine $k_{5}=(8.0 \pm 0.8)$ $\times 10^{9} \mathrm{M}^{-1} \mathrm{~s}^{-1}$. An estimated $10 \%$ error was reported.

${ }^{\mathrm{d}}$ Wagner et al. (1986), ${ }^{52} k_{5}=8.0 \times 10^{9} \mathrm{M}^{-1} \mathrm{~s}^{-1}$.

Wagner et $a l .{ }^{52}$ also used a delayed second laser to photolyze $\mathrm{Cl}_{2}^{-}$and monitor its relaxation, but they gave no experimental details. Their result agrees exactly with Nagaranjan and Fessenden, ${ }^{51}$ but no associated uncertainty was reported.

$$
\text { e Iwata and Yamanaka (1993), }{ }^{53} k_{5}=1.92
$$$$
\times 10^{10} \mathrm{M}^{-1} \mathrm{~s}^{-1} \text {. }
$$

Iwata and Yamanaka ${ }^{53}$ used laser flash photolysis of $\mathrm{Cl}^{-}$ solution at $193 \mathrm{~nm}$ to generate $\mathrm{Cl}_{2}^{-} \cdot$. The absorption signal obtained at $340 \mathrm{~nm}$ was the sum of contributions from both $\mathrm{Cl} \cdot$ and $\mathrm{Cl}_{2}^{-}$. Since the time constant of $\mathrm{Cl} \cdot$ is much faster than the detection limit in their experiments, they assumed that the rate of production of $\mathrm{Cl}$ - was proportional to the time-dependent laser fluence during the laser pulse. Under these assumptions they fitted the experimental data to obtain the quantum yield of $\mathrm{Cl} \cdot$, the formation rate of $\mathrm{Cl}_{2}^{-} \cdot$, and the molar extinction coefficients of $\mathrm{Cl} \cdot$ and $\mathrm{Cl}_{2}^{-} \cdot$. They found $k_{5}=1.92 \times 10^{10} \mathrm{M}^{-1} \mathrm{~s}^{-1}$, but did not report uncertainties. ${ }^{53}$

${ }^{\mathrm{f}}$ Buxton et al. $(1998),{ }^{12} k_{5}=(8.5 \pm 0.7) \times 10^{9} \mathrm{M}^{-1} \mathrm{~s}^{-1}$.

Buxton et al. ${ }^{12}$ determined $k_{5}$ directly by using laser flash photolysis of $\mathrm{Cl}^{-}$at $193 \mathrm{~nm}$ and monitoring the growth of $\mathrm{Cl}_{2}^{-} \cdot$ at $340 \mathrm{~nm}$. Since there were no competing reactions, the rate of $\mathrm{Cl}_{2}^{-} \cdot$ growth followed pseudo-first-order kinetics and gave $k_{5}=(8.5 \pm 0.7) \times 10^{9} \mathrm{M}^{-1} \mathrm{~s}^{-1} .{ }^{12}$ The uncertainty reported is most likely the statistical precision obtained in the least squares fits. Note that Iwata et al. ${ }^{53}$ and Buxton et al. ${ }^{12}$ employed virtually identical methods, but obtained results that differ by a factor of two. Buxton et al.'s measurement is in good agreement with the others described above.

${ }^{\mathrm{g}} \mathrm{Yu}$ and Barker (2003), ${ }^{6} k_{5}=(7.8 \pm 0.8) \times 10^{9} \mathrm{M}^{-1} \mathrm{~s}^{-1}$.

This is an unweighted average of experimental values
TABLE 9. Rate constant data of $k_{-5}$ by direct measurements

\begin{tabular}{lcccc}
\hline \hline$k_{-5}\left(\mathrm{~s}^{-1}\right)$ & Method & $p \mathrm{H}$ & Reference & Notes \\
\hline$(1.1 \pm 0.4) \times 10^{5}$ & Indirect & 0 & $1973^{9}$ & $\mathrm{a}$ \\
$7.6 \times 10^{5}$ & sim. & 7 & $1977^{54}$ & $\mathrm{~b}$ \\
$(6.0 \pm 0.5) \times 10^{4}$ & PR & $5-6$ & $1998^{12}$ & $\mathrm{c}$ \\
$(5.2 \pm 0.3) \times 10^{4}$ & LFP & 2 & $2003^{6}$ & $\mathrm{~d}$ \\
$(5.7 \pm 0.4) \times 10^{4}$ & ave. & - & $2003^{6}$ & $\mathrm{~d}$ \\
\hline
\end{tabular}

from notes $\mathrm{b}, \mathrm{c}, \mathrm{d}$, and $\mathrm{f}$.

\section{Preferred Values}

$k_{5}=(7.8 \pm 0.8) \times 10^{9} \mathrm{M}^{-1} \mathrm{~s}^{-1}$.

\section{Comments on Preferred Values}

The direct laser flash photolysis of $\mathrm{Cl}^{-}$is probably the best way to determine $k_{5}$. First, the chemical system does not contain species that compete with reaction (5). Second the pseudo-first-order fit of the observed formation rate constant requires few parameters and therefore there is less potential correlation among fitted parameters. On the basis of these considerations, we recommend the unweighted average of the direct determinations by Kläning and Wolff, ${ }^{48}$ Nagaranjan and Fessenden, ${ }^{51}$ Wagner et al. ${ }^{52}$ and Buxton et al.: ${ }^{12}$ $k_{5}=(7.8 \pm 0.8) \times 10^{9} \mathrm{M}^{-1} \mathrm{~s}^{-1}$.

\subsubsection{Reverse Rate Constant $\boldsymbol{k}_{-5}$}

There are only a few available results of $k_{-5}$. Notes (Table 9)

${ }^{\text {a }}$ Jayson et al. $(1973),{ }^{9} k_{-5}=(1.1 \pm 0.4) \times 10^{5} \mathrm{~s}^{-1}$.

The earliest value reported for $k_{-5}$ was by Jayson et al. ${ }^{9}$ who obtained $k_{-5}$ indirectly from their assumed diffusion controlled value for $k_{5}$ and their experimentally determined $K_{5}$. Their method for determining $K_{5}$ is described below. The actual experimental uncertainty in their value of $K_{5}$ ranges from $1.4 \times 10^{5}$ to $2.8 \times 10^{5} \mathrm{M}^{-1}$, which seriously affects the accuracy of $k_{-5}$.

${ }^{\mathrm{b}}$ Zansokhova et al. (1977), ${ }^{54} k_{-5}=7.6 \times 10^{5} \mathrm{~s}^{-1}$.

In a pulse radiolysis experiment, Zansokhova et al. ${ }^{54}$ reported $k_{-5}=7.6 \times 10^{5} \mathrm{M}^{-1}$ and $2 k_{6}=1.7 \times 10^{10} \mathrm{M}^{-1} \mathrm{~s}^{-1}$ as the best combination of the modeled and experimental relationship between $\left[\mathrm{Cl}_{2}^{-} \cdot\right]_{\max }$ and dose per pulse. The accuracy of $k_{-5}$ is correlated with that of $2 k_{6}$. Zansokhova et al. obtained a value for $2 k_{6}$ that is substantially larger than what was found in recent measurements. ${ }^{6,8,49,55,56}$ It is possible that the high result is due to correlations in the numerical analysis of their data. Therefore, it is likely that the accuracy of $k_{-5}$ is affected by the high value for $2 k_{6}$.

${ }^{\mathrm{c}}$ Buxton et al. $(1998),{ }^{12} k_{-5}=(6.0 \pm 0.5) \times 10^{4} \mathrm{~s}^{-1}$.

Buxton et al. ${ }^{12}$ determined $k_{-5}$ by examining the decay of $\mathrm{Cl}_{2}^{-}$. by pulse radiolysis of an aqueous solution containing $1 \times 10^{-3} \mathrm{M} \mathrm{Na}_{2} \mathrm{~S}_{2} \mathrm{O}_{8}$, chloride ions $\left(\left[\mathrm{Cl}^{-}\right] \geqslant 1 \times 10^{-3} \mathrm{M}\right)$ and $\mathrm{t}-\mathrm{BuOH}$. Chlorine atom and $\mathrm{Cl}_{2}^{-}$- readily react with the hydroxyl group of $\mathrm{t}-\mathrm{BuOH}$. These reactions compete with the reactions of $\mathrm{Cl} \cdot$ and $\mathrm{Cl}_{2}^{-}$- with $\mathrm{H}_{2} \mathrm{O}$. Buxton et al. found that the observed pseudo-first-order decay rate constant of $\mathrm{Cl}_{2}^{-} \cdot$ departed from linearity as the concentration of $\mathrm{t}-\mathrm{BuOH}$ increased due to the finite rate of reaction (5) in competition 
TABLE 10. Equilibrium constant data of $K_{5}$

\begin{tabular}{lcccc}
\hline \hline$K_{5}\left(\mathrm{M}^{-1}\right)$ & Method & $p \mathrm{H}$ & Reference & Notes \\
\hline$(1.1 \pm 0.4) \times 10^{5}$ & PR & 0 & $1973^{9}$ & $\mathrm{a}$ \\
17.7 & FP & N.A. & $1980^{10}$ & $\mathrm{~b}$ \\
$(4.7 \pm 0.4) \times 10^{3}$ & PR & neutral & $1995^{11}$ & $\mathrm{c}$ \\
$(1.4 \pm 0.1) \times 10^{5}$ & PR & $5-6$ & $1998^{12}$ & $\mathrm{~d}$ \\
$(1.4 \pm 0.2) \times 10^{5}$ & ave. & - & $2003^{6}$ & $\mathrm{e}$ \\
\hline
\end{tabular}

with the reactions with $\mathrm{t}-\mathrm{BuOH} .{ }^{12}$ By using their measured value of $k_{5}$ in a least-squares procedure, they determined $k_{-5}=(6.0 \pm 0.5) \times 10^{4} \mathrm{~s}^{-1}$.

${ }^{\mathrm{d}} \mathrm{Yu}$ and Barker $(2003),{ }^{6} k_{-5}=(5.2 \pm 0.3) \times 10^{4} \mathrm{~s}^{-1}$.

The pseudo-first-order decay rate constant of $\mathrm{Cl}_{2}^{-}$. was analyzed as a nonlinear function of $\left[\mathrm{H}_{2} \mathrm{O}_{2}\right]$ in the range of $0-0.01 \mathrm{M}$. The result obtained, $k_{-5}=(5.2 \pm 0.3) \times 10^{4} \mathrm{~s}^{-1}$, is not sensitive to the value of $k_{5}$. The analysis used is virtually the same as that by Buxton et al., although the reference reactions were different.

\section{Preferred Values}

$k_{-5}=(5.7 \pm 0.4) \times 10^{4} \mathrm{~s}^{-1}$.

\section{Comments on Preferred Values}

Because the errors from the results of Buxton et al. ${ }^{12}$ and Yu and Barker ${ }^{6}$ are likely to be of the same magnitude, we conclude that the best unbiased recommendation of $k_{-5}$ is the unweighted average of Buxton et al. ${ }^{12}$ and $\mathrm{Yu}$ and Barker. $^{6}$

\subsubsection{Equilibrium Constant $K_{5}$}

Notes (Table 10)

a Jayson et al. $(1973),{ }^{9} K_{5}=(1.1 \pm 0.4) \times 10^{5} \mathrm{M}^{-1}$.

Jayson et al. ${ }^{9}$ assumed that the optical absorption due to $\mathrm{Cl}_{2}^{-}$. had reached its maximum possible value when $[\mathrm{NaCl}]=0.01 \mathrm{M}$ and $\left[\mathrm{HClO}_{4}\right]=0.01 \mathrm{M}$. They then measured the absorption due to $\mathrm{Cl}_{2}^{-}$. under various other conditions of $[\mathrm{NaCl}]$ and $\left[\mathrm{HClO}_{4}\right]$ and expressed the results as functions of equilibrium constants $K_{3}, K_{4}$, and $K_{5}$. From among a range of algebraic solutions that described their data, they reported $K_{3} K_{4}=1.1 \times 10^{7} \mathrm{M}^{-1}$ and $K_{5}=1.9$ $\times 10^{5} \mathrm{M}^{-1}$. ${ }^{9}$ When all of the algebraic solutions are considered, $K_{5}$ falls in a rather wide range, i.e., $1.4 \times 10^{5}-2.8$ $\times 10^{5} \mathrm{M}^{-1}$. However, Jayson et al. ${ }^{9}$ did not explain how they arrived at their preferred value.

${ }^{\mathrm{b}} \mathrm{Wu}$ et al. $(1980),{ }^{10} K_{5}=17.7 \mathrm{M}^{-1}$.

The temperature dependence of $\mathrm{Cl}_{2}^{-} \cdot$ kinetics was studied. The $\mathrm{Cl}_{2}^{-}$- decay kinetics was analyzed by analogy with the $\mathrm{I}_{2}^{-}$- mechanism. Only second-order decay processes were considered in the $\mathrm{Cl}_{2}^{-}$- disappearance. The global secondorder decay constant was found to vary with $R$ $=1 / K_{5}\left[\mathrm{Cl}^{-}\right]$, a parameter defined by them. By varying $\left[\mathrm{Cl}^{-}\right], R$ approaches three categories: close to 0,0 , and much larger than 1 . The values of $k_{6}, k_{7}$, and that of $\mathrm{Cl} \cdot$ and $\mathrm{Cl} \cdot$ recombination reactions were obtained, respectively. The problem of this analysis is that only second-order decay was considered, which is inappropriate for the lower chloride conditions used in their experiments. A mixed first- and second-order decay mechanism is more suitable to describe $\mathrm{Cl}_{2}^{-}$. under low chloride concentration as supported by many recent findings. ${ }^{6,49,56}$

${ }^{\mathrm{c}}$ Adams et al. $(1995),{ }^{11} K_{5}=(4.7 \pm 0.4) \times 10^{3} \mathrm{M}^{-1}$.

This experiment assumed that $\mathrm{Cl}_{2}^{-}$. was the only absorbing species in a system containing $\mathrm{S}_{2} \mathrm{O}_{8}^{2-}, \mathrm{Cl}^{-}$, and $\left(\mathrm{CH}_{3}\right)_{3} \mathrm{COH}$ by pulse radiolysis. The $K_{5}$ was obtained by fitting the variance of $\mathrm{Cl}_{2}^{-} \cdot$ absorbance as a function of $1 /\left[\mathrm{Cl}^{-}\right]$. This approach may oversimplify the complicated $\mathrm{Cl}_{2}^{-} \cdot \mathrm{Cl} \cdot$ mechanism by assuming that the maximum absorbance is when all $\mathrm{Cl} \cdot$ are present as $\mathrm{Cl}_{2}^{-} \cdot$

${ }^{\mathrm{d}}$ Buxton et al. (1998), ${ }^{12} K_{5}=(1.4 \pm 0.1) \times 10^{5} \mathrm{M}^{-1}$.

Buxton et al. ${ }^{12}$ directly determined $k_{5}$ and $k_{-5}$ (discussions seen in Secs. 4.7.1 and 4.7.2). By using their experimental values of $k_{5}$ and $k_{-5}, K_{5}$ was derived.

${ }^{\mathrm{e}} \mathrm{Yu}$ and Barker (2003), ${ }^{6} K_{5}=(1.4 \pm 0.2) \times 10^{5} \mathrm{M}^{-1}$.

The equilibrium constant was obtained from the ratio of forward and reverse rate constants. The recommended values of $k_{5}$ and $k_{-5}$ are $(7.8 \pm 0.8) \times 10^{9} \mathrm{M}^{-1} \mathrm{~s}^{-1}$ and $(5.7 \pm 0.4)$ $\times 10^{4} \mathrm{~s}^{-1}$, respectively. The ratio of these values gives $K_{5}$ $=(1.4 \pm 0.2) \times 10^{5} \mathrm{M}^{-1}$, where the uncertainty was obtained by error propagation.

\section{Preferred Values}

$$
K_{5}=(1.4 \pm 0.2) \times 10^{5} \mathrm{M}^{-1} \text {. }
$$

\section{Comments on Preferred Values}

The result of Yu and Barker ${ }^{6}$ result is in good agreement with that of Buxton et al. ${ }^{12}$ both of which agree with the result of Jayson et al. ${ }^{9}$ The unweighted average of results from Buxton et al. ${ }^{12}$ and $\mathrm{Yu}$ and Barker ${ }^{6}$ is recommended as the best unbiased estimate of $K_{5}$. Although this numerical value is not much different from that of Jayson et al., ${ }^{9}$ the uncertainty of $K_{5}$ is much improved. With the recommended $K_{5}$ and the standard reduction potential $E\left(\mathrm{Cl} \cdot / \mathrm{Cl}^{-}\right)$ $=2.41 \mathrm{~V},{ }^{57}$ the standard reduction potential $E\left(\mathrm{Cl}_{2}^{-} \cdot / 2 \mathrm{Cl}^{-}\right)$ $=2.11 \mathrm{~V}$ is obtained, which differs only slightly from the value obtained using the equilibrium constant from Jayson et al. ${ }^{9}\left(E\left(\mathrm{Cl}_{2}^{-} \cdot / 2 \mathrm{Cl}^{-}\right)=2.09 \mathrm{~V}\right)$ as expected.

\section{8. $k_{6}, \mathrm{Cl}_{2}^{-} \cdot+\mathrm{Cl}_{2}^{-} \cdot \rightarrow 2 \mathrm{Cl}^{-}+\mathrm{Cl}_{2}$}

Since various extinction coefficients of $\mathrm{Cl}_{2}^{-}$- were taken due to differences in monitor wavelength and arbitrary decisions, more attention should be directed to the ratio $2 k_{6} / \varepsilon$ instead of the derived value $k_{6}$ itself. The $2 k_{6} / \varepsilon$ falls into a fair range, i.e., from $1.1 \times 10^{4}$ to $1.4 \times 10^{6} \mathrm{~cm} \mathrm{~s}^{-1}$. Most of the previous studies of $\mathrm{Cl}_{2}^{-}$- decay consider it primarily a second-order process. When a more complicated kinetics scheme was applied, it is noted in the comment.

Notes (Table 11)

a Langmuir and Hayon (1967), ${ }^{58} k_{6}=(0.75 \pm 0.05)$ $\times 10^{10} \mathrm{M}^{-1} \mathrm{~s}^{-1}(p \mathrm{H}=6)$ and $(0.69 \pm 0.1) \times 10^{10} \mathrm{M}^{-1} \mathrm{~s}^{-1}$ $(p \mathrm{H}=1.1)$.

The $k_{6}$ was obtained by flash photolysis of $\mathrm{NaCl}, \mathrm{HgCl}_{2}$, and $\mathrm{HgCl}_{4}^{2-}$, respectively. The authors considered their $k_{6}$ values the same within experimental error. In Table 11, the unweighted average of the reported values from their work is listed. 
TABLE 11. Rate constant data of $k_{6}$

\begin{tabular}{|c|c|c|c|c|c|c|c|c|}
\hline $\begin{array}{l}k_{6} \times 10^{-9} \\
\left(\mathrm{M}^{-1} \mathrm{~s}^{-1}\right)\end{array}$ & $I(\mathrm{M})$ & $p \mathrm{H}$ & $\begin{array}{c}\left(2 k_{6} / \varepsilon\right) \times 10^{-5} \\
\left(\mathrm{~cm} \mathrm{~s}^{-1}\right)\end{array}$ & $\left(\mathrm{M}^{-1} \mathrm{~cm}^{-1}\right)$ & $\begin{array}{c}\lambda \\
(\mathrm{nm})\end{array}$ & Method & Reference & Notes \\
\hline $7.05 \pm 0.6$ & 0.5 & $1.1-6.0$ & $11.3 \pm 1.0$ & 12500 & 360 & FP & $1967^{58}$ & $\mathrm{a}$ \\
\hline $7 \pm 1.5$ & N.A. & $0.9-3.2$ & 7 & 10000 & 360 & PR & $1968^{44}$ & $\mathrm{~b}$ \\
\hline $6 \pm 1.5$ & 0.1 & 1.9 & N.A. & N.A. & 340 & PR & $1972^{59}$ & $\mathrm{c}$ \\
\hline 5.2 & 0.2 & $0.3-1$ & 8.4 & 12500 & 340 & FP & $1973^{60}$ & $\mathrm{~d}$ \\
\hline $7.5 \pm 0.5$ & $>10$ & $\sim 7$ & $12.1 \pm 0.8$ & 12400 & 340 & PR & $1974^{61}$ & $\mathrm{e}$ \\
\hline $2.7 \pm 0.5$ & $1.5-14$ & 7 & 6.2 & 8700 & 340 & PR & $1975^{62}$ & $\mathrm{f}$ \\
\hline $6.5 \pm 2.5$ & N.A. & N.A. & $10.5 \pm 4.1$ & 12400 & 340 & PR & $1976^{63}$ & $\mathrm{~g}$ \\
\hline 8.5 & N.A. & N.A. & 13.7 & 12400 & 340 & PR & $1977^{54}$ & $\mathrm{~h}$ \\
\hline 3.85 & $\leqslant 2$ & N.A. & 6.6 & 12000 & 340 & PR & $1980^{10}$ & $\mathrm{i}$ \\
\hline $2.0 \pm 0.2$ & 0.2 & $\sim 2$ & $4.54 \pm 0.45$ & 8800 & 340 & PR & $1980^{64}$ & $\mathrm{j}$ \\
\hline $1.0-1.85$ & $1-12$ & $<0$ & $2.5-4.6$ & 8000 & 360 & PR & $1984^{65}$ & $\mathrm{k}$ \\
\hline 1.15 & - & - & - & - & - & calc. & $1986^{52}$ & 1 \\
\hline $0.07 \pm 0.035$ & - & - & $0.11 \pm 0.05$ & 12500 & 340 & sim. & $1986^{52}$ & 1 \\
\hline $6 \pm 2$ & N.A. & N.A. & $9.6 \pm 3.2$ & 12500 & 340 & $\mathrm{FP}$ & $1986^{66}$ & $\mathrm{~m}$ \\
\hline $2.25 \pm 0.1$ & 1 & 3 & $5.56 \pm 0.25$ & 8100 & 340 & PR & $1987^{67}$ & $\mathrm{n}$ \\
\hline $5.5 \pm 3.5$ & 0.25 & 5.5 & $8.8 \pm 5.6$ & 12500 & 340 & FP & $1981^{68}$ & o \\
\hline $1.55 \pm 0.05$ & 0.13 & 2.2 & $3.65 \pm 0.12$ & 8800 & 340 & PR & $1990^{49}$ & $\mathrm{p}$ \\
\hline $0.7 \pm 0.1$ & 0 & N.A. & 1.6 & 8800 & 340 & LFP & $1990^{49}$ & $\mathrm{p}$ \\
\hline 1.3 & 0 & N.A. & 2.96 & 8800 & 340 & LFP & $1990^{55}$ & $q$ \\
\hline $0.69 \pm 0.005$ & 0 & N.A. & $1.57 \pm 0.01$ & 8800 & 340 & LFP & $1997^{69}$ & $\mathrm{r}$ \\
\hline $1.8 \pm 0.1$ & 0 & 4 & $4.24 \pm 0.24$ & 8300 & 325 & LFP & $1999^{56}$ & $\mathrm{~s}$ \\
\hline 0.61 & 0 & $2.05-3.0$ & 1.27 & 9600 & 364 & LFP & $2000^{70}$ & $\mathrm{t}$ \\
\hline $0.65 \pm 0.14$ & 0 & & & N.A. & 350 & LFP & $2002^{71}$ & $\mathrm{u}$ \\
\hline $0.72 \pm 0.08$ & 0 & 2 & $2.06 \pm 0.27$ & 7000 & 340 & LFP & $2003^{6}, 2004^{8}$ & $\mathrm{~V}$ \\
\hline $2.0 \pm 0.3$ & N.A. & N.A. & $4.55 \pm 0.76$ & 8800 & 340 & PR & $2003^{72}$ & $\mathrm{w}$ \\
\hline
\end{tabular}

b Ward and Kuo (1968), ${ }^{44} \quad k_{6}=(0.7 \pm 0.15)$ $\times 10^{10} \mathrm{M}^{-1} \mathrm{~s}^{-1}$.

No $p \mathrm{H}$ dependence of $k_{6}$ was found between $p \mathrm{H} 0.9$ and 3.2 .

c Patterson et al. (1972), ${ }^{59} \quad k_{6}=(0.6 \pm 0.15)$ $\times 10^{10} \mathrm{M}^{-1} \mathrm{~s}^{-1}$.

In the presence of pyrimidine, the $\mathrm{Cl}_{2}^{-} \cdot$ self-reaction rate was determined. It was suggested that $\mathrm{Cl}_{2}^{-}$- oxidized the pyrimidine molecule.

d Thornton and Laurence (1973), ${ }^{60} \quad k_{6}=0.52$ $\times 10^{10} \mathrm{M}^{-1} \mathrm{~s}^{-1}$.

The $\mathrm{Cl}_{2}^{-}$was formed by complex $\mathrm{FeCl}^{2+}$ dissociation and the subsequent reaction between one of the dissociation products $\mathrm{Cl} \cdot$ and $\mathrm{Cl}^{-}$.

e Zhestkova and Pikaev (1974), ${ }^{61} \quad k_{6}=(0.75 \pm 0.05)$ $\times 10^{10} \mathrm{M}^{-1} \mathrm{~s}^{-1}$.

This value was obtained at high ionic strength, i.e., $\left[\mathrm{Cl}^{-}\right]>10 \mathrm{M}$. Because when $\left[\mathrm{Cl}^{-}\right]<1 \mathrm{M}$, the signal to noise ratio was high and the yield of $\mathrm{Cl}_{2}^{-}$. was low.

${ }^{\mathrm{f}}$ Woods et al. $(1975),{ }^{62} k_{6}=(2.7 \pm 0.5) \times 10^{10} \mathrm{M}^{-1} \mathrm{~s}^{-1}$.

The ratio $2 k_{6} / \varepsilon$ was found to vary very little over the range of concentrations studied, i.e., $1.5 \mathrm{M}<[\mathrm{NaCl}]$ $<14 \mathrm{M}$.

g Broszkiewicz (1976), ${ }^{63} \quad k_{6}=(0.65 \pm 0.25)$ $\times 10^{10} \mathrm{M}^{-1} \mathrm{~s}^{-1}$.

Only second-order decay of $\mathrm{Cl}_{2}^{-}$. was considered.

${ }^{\mathrm{h}}$ Zansokhova et al. (1977), ${ }^{54} k_{6}=0.85 \times 10^{10} \mathrm{M}^{-1} \mathrm{~s}^{-1}$.

Both $k_{6}=0.85 \times 10^{10} \mathrm{M}^{-1} \mathrm{~s}^{-1}$ and $k_{-5}=7.6$ $\times 10^{5} \mathrm{M}^{-1} \mathrm{~s}^{-1}$ were obtained by computer calculated de- pendence of $\left[\mathrm{Cl}_{2}^{-} \cdot\right]_{\max }$ on dose per pulse with the best convergence.

${ }^{\mathrm{i}} \mathrm{Wu}$ et al. $(1980),{ }^{10} k_{6}=3.85 \times 10^{9} \mathrm{M}^{-1} \mathrm{~s}^{-1}$.

The second-order component of $\mathrm{Cl}_{2}^{-}$. was considered as a function of $\left[\mathrm{Cl}^{-}\right]$.

j Navaratnam et al. (1980), ${ }^{64} \quad k_{6}=(2.0 \pm 0.2)$ $\times 10^{9} \mathrm{M}^{-1} \mathrm{~s}^{-1}$,

The rate constants of reactions (6) and (11) were simultaneously determined from the theoretical log-linear plots calculated for various combinations of rate constants of reactions (6) and (11).

$\mathrm{k}$ Gogolev et al. (1980), ${ }^{65} \quad k_{6}=(1.0-1.85)$ $\times 10^{9} \mathrm{M}^{-1} \mathrm{~s}^{-1}$.

A range of $k_{6}$ was obtained under concentrated $\mathrm{HCl}$ conditions. The observed second-order rate constant was considered the sum of rate constants of reactions (6) and (11).

${ }^{1}$ Wagner et al. (1986), ${ }^{52} k_{6}=1.15 \times 10^{9} \mathrm{M}^{-1} \mathrm{~s}^{-1}$ (calculated) and $k_{6}=(0.7 \pm 0.35) \times 10^{8} \mathrm{M}^{-1} \mathrm{~s}^{-1}$ (simulated). Two results were reported. One was calculated assuming diffusion control between two identical ions $[Z=-1, \quad D=0.7$ $\times 10^{-5} \mathrm{~cm}^{-2} \mathrm{~s}^{-1}$ (estimated) and a distance of closest approach $a=3.5 \times 10^{10} \mathrm{~m}$, the other was obtained by simulation of a mechanism containing 30 reactions, some of which are listed in the discussion of $k_{8}\left[\mathrm{H}_{2} \mathrm{O}\right]$ below.

m Slama-Schwok and Rabani (1986), ${ }^{66} \quad k_{6}=0.6$ $\times 10^{10} \mathrm{M}^{-1} \mathrm{~s}^{-1}$.

The $k_{6}=0.6 \times 10^{10} \mathrm{M}^{-1} \mathrm{~s}^{-1}$ was obtained by the $\mathrm{Cl}_{2}^{-} \cdot$ decay generated by the complex $\left.\left[\operatorname{Ir}\left(\mathrm{C} 3, \mathrm{~N}^{\prime}-\mathrm{Hbpy}\right)(\mathrm{bpy})_{2}\right)\right]^{4+}$ 
TABLE 12. Rate constant data of $k_{7}$

\begin{tabular}{|c|c|c|c|c|c|c|c|}
\hline $\begin{array}{l}k_{7} \times 10^{-9} \\
\left(\mathrm{M}^{-1} \mathrm{~s}^{-1}\right)\end{array}$ & $p \mathrm{H}$ & $\begin{array}{c}\left(2 k_{7} / \varepsilon\right) \times 10^{-5} \\
\left(\mathrm{~cm} \mathrm{~s}^{-1}\right)\end{array}$ & $\begin{array}{c}\lambda \\
(\mathrm{nm})\end{array}$ & $\begin{array}{c}\varepsilon \\
\left(\mathrm{M}^{-1} \mathrm{~cm}^{-1}\right)\end{array}$ & Method & Reference & Notes \\
\hline 0.625 & N.A. & 1.04 & 340 & 12000 & PR & $1980^{10}$ & $\mathrm{a}$ \\
\hline $2.1 \pm 0.05$ & 2 & $2.54 \pm 0.16$ & 364 & 7000 & LFP & $2003^{6}$ & $\mathrm{~b}$ \\
\hline
\end{tabular}

reacting with $\mathrm{Cl}^{-}$identified to be a mixed first- and secondorder process. However, the above result was obtained ignoring the first-order component.

${ }^{\mathrm{n}}$ Lierse et al. $(1987),{ }^{67} k_{6}=(2.25 \pm 0.1) \times 10^{9} \mathrm{M}^{-1} \mathrm{~s}^{-1}$.

The $k_{6}=(2.25 \pm 0.1) \times 10^{9} \mathrm{M}^{-1} \mathrm{~s}^{-1}$ was obtained by pulse radiolysis of $\mathrm{UO}_{2}\left(\mathrm{ClO}_{2}\right)_{2}$ containing $\mathrm{NaCl}$ at $p \mathrm{H} 3$. The reactions between $\mathrm{Cl}_{2}^{-}$- and $\mathrm{UO}_{2}^{+}$and $\mathrm{Cl}_{2}^{-} \cdot$ and $\mathrm{H}$ were considered insignificant compared to the $\mathrm{Cl}_{2}^{-} \cdot$ self reaction.

${ }^{\circ}$ Hynes and Wine (1988), ${ }^{68} \quad k_{6}=(5.5 \pm 2)$ $\times 10^{9} \mathrm{M}^{-1} \mathrm{~s}^{-1}$.

The $k_{6}=(5.5 \pm 2) \times 10^{9} \mathrm{M}^{-1} \mathrm{~s}^{-1}$ was solved on the basis of a pure second-order kinetics.

p McElroy $(1990),{ }^{49} \quad k_{6}=(0.7 \pm 0.1) \times 10^{9} \mathrm{M}^{-1} \mathrm{~s}^{-1} \quad(I$ $=0 \mathrm{M})$ and $(1.55 \pm 0.05) \times 10^{9} \mathrm{M}^{-1} \mathrm{~s}^{-1}(I=0.13 \mathrm{M})$.

McElroy reported two values of $k_{6}$. One is the average with no ionic strength justification, $k_{6}=(1.55 \pm 0.05)$ $\times 10^{9} \mathrm{M}^{-1} \mathrm{~s}^{-1}$. The other is $k_{6}=(0.7 \pm 0.1) \times 10^{9} \mathrm{M}^{-1} \mathrm{~s}^{-1}$ by extrapolating data to infinite dilution.

${ }^{\mathrm{q}}$ Huie and Clifton (1990), ${ }^{55} k_{6}=1.3 \times 10^{9} \mathrm{M}^{-1} \mathrm{~s}^{-1}$.

This result is an average of a set of results on $k_{6}$ corrected to zero ionic strength.

${ }^{\mathrm{r}}$ Bao $(1997),{ }^{69} k_{6}=(0.69 \pm 0.005) \times 10^{9} \mathrm{M}^{-1} \mathrm{~s}^{-1}$.

The ionic strength dependence of $k_{6}$ was investigated by adding $\mathrm{NaClO}_{4}$ to vary the ionic strength of the solution. This result was justified to zero ionic strength.

${ }^{\mathrm{s}}$ Jacobi et al. $(1991),{ }^{56} k_{6}=(1.8 \pm 0.1) \times 10^{9} \mathrm{M}^{-1} \mathrm{~s}^{-1}$.

The details of this measurement were not available except that $k_{6}$ was corrected to zero ionic strength. The $2 k_{6} / \varepsilon$ is derived based upon the reported value and the molar extinction coefficient used in the same work.

${ }^{\mathrm{t}}$ Alegre et al. $(2000),{ }^{70} k_{6}=0.61 \times 10^{9} \mathrm{M}^{-1} \mathrm{~s}^{-1}$.

The Debye-Hückle relationship was observed up to $0.5 \mathrm{M}$ ionic strength.

u Christian and Chovelon (2002), ${ }^{71} k_{6}=(0.65 \pm 0.14)$ $\times 10^{9} \mathrm{M}^{-1} \mathrm{~s}^{-1}$.

This second-order rate constant is obtained under conditions favoring second-order decay of $\mathrm{Cl}_{2}^{-} \cdot$, and it is adjusted to zero ionic strength. The uncertainty is calculated within $\pm 2 \sigma$. The extinction coefficient of $\mathrm{Cl}_{2}^{-} \cdot$ used to derive $k_{6}$ is not mentioned.

${ }^{\mathrm{v}} \mathrm{Yu}$ and Barker $(2003)^{6}$ and Yu et al. (2004), ${ }^{8} k_{6}=(0.72$ $\pm 0.08) \times 10^{9} \mathrm{M}^{-1} \mathrm{~s}^{-1}$.

The $2 k_{6} / \varepsilon$ was obtained by mixed first- and second-order analysis of the decay trace of $\mathrm{Cl}_{2}^{-}$- in the photolysis of acidic solutions containing $\mathrm{Cl}^{-}$and $\mathrm{H}_{2} \mathrm{O}_{2}{ }^{6}$ and $\mathrm{Cl}^{-}$and $\mathrm{K}_{2} \mathrm{~S}_{2} \mathrm{O}_{8}{ }^{8}$ respectively. The ionic strength of all experiments was approximately $0.01 \mathrm{M}$ or lower. Under such conditions, $k_{6}$ $=(0.9 \pm 0.05) \times 10^{9} \mathrm{M}^{-1} \mathrm{~s}^{-1}$ was obtained using $\varepsilon_{\mathrm{Cl}_{2}^{-}, 364 \mathrm{~nm}}$ $=7000 \mathrm{M}^{-1} \mathrm{~cm}^{-1} \cdot{ }^{8}$ When adjusted by infinite dilution, $k_{6}$
$=(0.72 \pm 0.08) \times 10^{9} \mathrm{M}^{-1} \mathrm{~s}^{-1}$ was obtained. The temperature dependence of $k_{6}$ in the range of $6.8-51.6^{\circ} \mathrm{C}$ is reported.

${ }^{w}$ Poskrevbyshev et al. (2003), ${ }^{72} \quad k_{6}=(2.0 \pm 0.3)$ $\times 10^{9} \mathrm{M}^{-1} \mathrm{~s}^{-1}$.

The $\mathrm{Cl}_{2}^{-}$- was generated by pulse radiolysis of solutions containing $\mathrm{Cl}^{-}$and $\mathrm{HNO}_{3}$. The $\mathrm{Cl}_{2}^{-}$. follows a second-order rate law with increased $\left[\mathrm{Cl}^{-}\right]$.

\section{Preferred Values}

$2 k_{6} / \varepsilon=(6.5 \pm 2.5) \times 10^{5} \mathrm{~cm} \mathrm{~s}^{-1}(340 \mathrm{~nm})$.

$2 k_{6} / \varepsilon=(5.0 \pm 3.7) \times 10^{5} \mathrm{~cm} \mathrm{~s}^{-1}(\sim 360 \mathrm{~nm})$.

$k_{6}=(3.5 \pm 2.7) \times 10^{9} \mathrm{M}^{-1} \mathrm{~s}^{-1}$.

\section{Comments on Preferred Values}

The preferred values of $2 k_{6} / \varepsilon$ are categorized in two groups considering the probe wavelength of $\mathrm{Cl}_{2}^{-} \cdot$, i.e., 340 and $\sim 360 \mathrm{~nm}$. They are both unweighted average of reported results. The unweighted average of $k_{6}$ is obtained from all reported values except the very low value from Wagner et al., because it is an outlier compared to other reports. Values are taken as reported with no further ionic strength correction.

\section{9. $k_{7}, \mathrm{Cl} \cdot+\mathrm{Cl}_{2}^{-} \cdot \rightarrow \mathrm{Cl}^{-}+\mathrm{Cl}_{2}$}

The rate constant data of $k_{7}$ is in Table 12 .

Notes (Table 12)

${ }^{\mathrm{a}} \mathrm{Wu}$ et al. $(1980),{ }^{10} k_{7}=0.625 \times 10^{9} \mathrm{M}^{-1} \mathrm{~s}^{-1}$.

Wu et al. studied the second-order dependence of $\mathrm{Cl}_{2}^{-} \cdot$ as a function of $\left[\mathrm{Cl}^{-}\right]$. Detailed description of this analysis is in Sec. 4.7.3.

b $\mathrm{Yu}$ and Barker (2004), ${ }^{8} \quad k_{7}=(2.1 \pm 0.05)$ $\times 10^{9} \mathrm{M}^{-1} \mathrm{~s}^{-1}$.

The second-order decay rate constant of $\mathrm{Cl}_{2}^{-} \cdot$ was found to depend on $\left[\mathrm{Cl}^{-}\right]$. The $2 k_{6} / \varepsilon$ and $4 k_{7} / \varepsilon$ were obtained from the linear least squares fit of the $\mathrm{Cl}_{2}^{-}$. second-order decay rate constant as a function of $1 /\left[\mathrm{Cl}^{-}\right] .8$

\section{Preferred Values}

$k_{7}=(1.4 \pm 1.0) \times 10^{9} \mathrm{M}^{-1} \mathrm{~s}^{-1}$

\section{Comments on Preferred Values}

The preferred value is the unweighted average of the two reported values.

\subsection{0. $k_{8}\left[\mathrm{H}_{2} \mathrm{O}\right], \mathrm{Cl}_{2}^{-} \cdot+\mathrm{H}_{2} \mathrm{O} \rightarrow \mathrm{ClOH}^{-} \cdot+\mathrm{H}^{+}+\mathrm{Cl}^{-}$}

Similar to $k_{-4}$, most of the literature reported $k_{8}\left[\mathrm{H}_{2} \mathrm{O}\right]$. The rate constant data of $k_{8}\left[\mathrm{H}_{2} \mathrm{O}\right]$ is in Table 13 .

Notes (Table 13)

${ }^{\mathrm{a}}$ Wagner et al. (1986), ${ }^{52} k_{8}\left[\mathrm{H}_{2} \mathrm{O}\right]=7.2 \times 10^{3} \mathrm{~s}^{-1}$. 
TABLE 13. Rate constant data of $k_{8}\left[\mathrm{H}_{2} \mathrm{O}\right]$

\begin{tabular}{lccccc}
\hline \hline$k_{8}\left[\mathrm{H}_{2} \mathrm{O}\right]\left(\mathrm{s}^{-1}\right)$ & Method & $I, M$ & $p \mathrm{H}$ & Reference & Notes \\
\hline$(7.20 \pm 1.44) \times 10^{3}$ & FP & N.A. & N.A. & $1986^{52}$ & $\mathrm{a}$ \\
$(1.3 \pm 0.1) \times 10^{3}$ & PR & 0.13 & $\sim 4$ & $1990^{49}$ & $\mathrm{~b}$ \\
$<610$ & LFP & $\sim 0.1$ & 4 & $1997^{50}$ & $\mathrm{c}$ \\
$(1.3 \pm 0.1) \times 10^{3}$ & PR & N.A. & $5-6$ & $1998^{12}$ & $\mathrm{~d}$ \\
$<100$ & LFP & N.A. & 2 & $2003^{6}$ & $\mathrm{e}$ \\
$<100$ & LFP & N.A. & 2 & $2004^{8}$ & $\mathrm{f}$ \\
\hline
\end{tabular}

The experimental technique is to measure the change of conductivity caused by the change of charge of certain radical products after photolysis of chloride ions in acidic solutions. A system containing the following reactions:

$$
\begin{gathered}
\mathrm{Cl} \cdot+\mathrm{Cl}^{-} \leftrightarrow \mathrm{Cl}_{2}^{-}, \\
e^{-}+\mathrm{H}^{+} \rightarrow \mathrm{H} \cdot, \\
\mathrm{H} \cdot+\mathrm{H} \cdot \rightarrow \mathrm{H}_{2}, \\
e^{-}+\mathrm{Cl}_{2}^{-} \cdot \rightarrow 2 \mathrm{Cl}^{-}, \\
\mathrm{HO} \cdot+\mathrm{H} \cdot \rightarrow \mathrm{H}_{2} \mathrm{O}, \\
\mathrm{Cl}_{2}^{-} \cdot+\mathrm{H} \cdot \rightarrow \mathrm{H}^{+}+2 \mathrm{Cl}^{-}, \\
\mathrm{HO} \cdot+\mathrm{HO} \cdot \rightarrow \mathrm{H}_{2} \mathrm{O}_{2}, \\
\mathrm{Cl}_{2}^{-} \cdot+\mathrm{Cl}_{2}^{-} \cdot \rightarrow \mathrm{Cl}_{2}+2 \mathrm{Cl}^{-}, \\
\mathrm{Cl}_{2}+\mathrm{H}_{2} \mathrm{O} \leftrightarrow \mathrm{HOCl}+\mathrm{H}^{+}+\mathrm{Cl}^{-}, \\
\mathrm{Cl}_{2}^{-} \cdot+\mathrm{H}_{2} \mathrm{O} \leftrightarrow \mathrm{HO} \cdot+\mathrm{H}^{+}+2 \mathrm{Cl}^{-}, \\
\mathrm{Cl}_{2}^{-} \cdot+\mathrm{HO} \cdot \rightarrow \mathrm{HOCl}+\mathrm{Cl}^{-},
\end{gathered}
$$

was used to simulate experimental data. The $k_{8}\left[\mathrm{H}_{2} \mathrm{O}\right]$ was obtained from the best set of rate constants fitting the experimental results, i.e., $k_{15}, k_{17}, k_{19}, k_{20}, k_{22}, k_{23}$. The system is complex. The whole system was integrated using a fourthorder Runge-Kutta method.

${ }^{\text {b }}$ McElroy $(1990),{ }^{49} k_{8}\left[\mathrm{H}_{2} \mathrm{O}\right]=(1.3 \pm 0.1) \times 10^{3} \mathrm{~s}^{-1}$.

McElroy considered the following reactions for the pseudo-first-order decay of $\mathrm{Cl}_{2}^{-} \cdot$

$$
\begin{aligned}
& \mathrm{Cl}_{2}^{-} \cdot \leftrightarrow \mathrm{Cl} \cdot+\mathrm{Cl}^{-}, \\
& \mathrm{Cl} \cdot+\mathrm{H}_{2} \mathrm{O} \leftrightarrow \mathrm{H}^{+}+\mathrm{ClOH}^{-}, \\
& \mathrm{ClOH}^{-} \cdot \leftrightarrow \mathrm{HO} \cdot+\mathrm{Cl}^{-},
\end{aligned}
$$

and the overall process was described by reaction (24)

$$
\mathrm{Cl}_{2}^{-} \cdot+\mathrm{H}_{2} \mathrm{O} \leftrightarrow \mathrm{HO} \cdot+\mathrm{H}^{+}+2 \mathrm{Cl}^{-} .
$$

The $k_{8}\left[\mathrm{H}_{2} \mathrm{O}\right]=(1.3 \pm 0.1) \times 10^{3} \mathrm{~s}^{-1}$ was determined as a lower limit of the observed decay rate constant of $\mathrm{Cl}_{2}^{-} \cdot$ when $\left[\mathrm{Cl}^{-}\right]>1 \times 10^{-2} \mathrm{M}$, because $k_{\mathrm{obs}}$ increases markedly under conditions of $\left[\mathrm{Cl}^{-}\right]<1 \times 10^{-3} \mathrm{M}$. Essentially, the analytical strategy is the same as in the recent work by Yu and Barker, ${ }^{6}$ albeit the mathematical function was written in a different form.

${ }^{\mathrm{c}}$ Jacobi et al. $(1997),{ }^{50} k_{8}\left[\mathrm{H}_{2} \mathrm{O}\right]<610 \mathrm{~s}^{-1}$.
Jacobi et al. ${ }^{50}$ has compared their results by photolysis of chloride ions and persulfate ions with the earlier results (notes a and $\mathrm{b})^{49,52}$ and given possible explanation on this discrepancy. The decay of $\mathrm{Cl}_{2}^{-}$- was considered to include $\mathrm{Cl} \cdot+\mathrm{H}_{2} \mathrm{O}, \mathrm{Cl}_{2}^{-} \cdot+\mathrm{H}_{2} \mathrm{O}$, and $\mathrm{Cl}_{2}^{-} \cdot+\mathrm{Cl}_{2}^{-} \cdot$. The equilibrium of $\mathrm{Cl} \cdot+\mathrm{Cl}^{-} \leftrightarrow \mathrm{Cl}_{2}^{-} \cdot$ was assumed to be maintained. The $k_{8}\left[\mathrm{H}_{2} \mathrm{O}\right]$ and $k_{4}\left[\mathrm{H}_{2} \mathrm{O}\right] / K_{5}$ were obtained from the linear least squares fit to the observed pseudo-first-order rate constant.

${ }^{\mathrm{d}}$ Buxton et al. (1998), ${ }^{12} k_{8}\left[\mathrm{H}_{2} \mathrm{O}\right]=(1.3 \pm 0.1) \times 10^{3} \mathrm{~s}^{-1}$.

Pulse radiolysis of $\mathrm{Cl}^{-}$and $\mathrm{S}_{2} \mathrm{O}_{8}^{2-}$ was used to form $\mathrm{Cl}_{2}^{-}$. The system contains t-BuOH, therefore, the decay of $\mathrm{Cl}_{2}^{-}$. included $\mathrm{Cl} \cdot+\mathrm{H}_{2} \mathrm{O}, \mathrm{Cl} \cdot+\mathrm{t}-\mathrm{BuOH}, \mathrm{Cl}_{2}^{-} \cdot+\mathrm{H}_{2} \mathrm{O}$, and $\mathrm{Cl}_{2}^{-}$. $+\mathrm{t}-\mathrm{BuOH}$. The pseudo-first-order decay rate constant was analyzed as a function of $\left[\mathrm{H}_{2} \mathrm{O}\right]$ and $[\mathrm{t}-\mathrm{BuOH}]$. The linear part of this function generated two other relationships, i.e., intercept and slope. The $k_{-4}\left[\mathrm{H}_{2} \mathrm{O}\right] / K_{5}$ and $k_{8}\left[\mathrm{H}_{2} \mathrm{O}\right]$ were obtained from the linear least squares fit of the slopes from $k_{\mathrm{obs}}$ versus $[\mathrm{t}-\mathrm{BuOH}]$ analysis with respect to $1 /\left[\mathrm{Cl}^{-}\right]$.

${ }^{\mathrm{e}} \mathrm{Yu}$ and Barker (2003), ${ }^{6} k_{8}\left[\mathrm{H}_{2} \mathrm{O}\right]<100 \mathrm{~s}^{-1}$.

Laser flash photolysis of $\mathrm{H}_{2} \mathrm{O}_{2}$ and $\mathrm{Cl}^{-}$under acidic conditions was studied. The $\mathrm{Cl}_{2}^{-} \cdot$ decay consists of $\mathrm{Cl} \cdot+\mathrm{H}_{2} \mathrm{O}$, $\mathrm{Cl} \cdot+\mathrm{H}_{2} \mathrm{O}_{2}, \mathrm{Cl}_{2}^{-} \cdot+\mathrm{H}_{2} \mathrm{O}$, and $\mathrm{Cl}_{2}^{-} \cdot+\mathrm{H}_{2} \mathrm{O}_{2}$. An analysis similar to that of Buxton et al. ${ }^{12}$ was applied. The $k_{-4}\left[\mathrm{H}_{2} \mathrm{O}\right] K_{5}$ and $k_{8}\left[\mathrm{H}_{2} \mathrm{O}\right]$ were obtained from linear least squares fit of the slopes of the $k_{\text {obs }}$ versus $\left[\mathrm{H}_{2} \mathrm{O}_{2}\right]$ analysis with respect to $1 /\left[\mathrm{Cl}^{-}\right]$.

${ }^{\mathrm{f}} \mathrm{Yu}$ and Barker (2004), ${ }^{8} k_{8}\left[\mathrm{H}_{2} \mathrm{O}\right]<100 \mathrm{~s}^{-1}$.

Laser flash photolysis of $\mathrm{S}_{2} \mathrm{O}_{8}^{2-}$ and $\mathrm{Cl}^{-}$under acidic conditions was used. The $\mathrm{Cl}_{2}^{-} \cdot$ decay consists of $\mathrm{Cl} \cdot+\mathrm{H}_{2} \mathrm{O}$, $\mathrm{Cl} \cdot+\mathrm{S}_{2} \mathrm{O}_{8}^{2-}, \quad \mathrm{Cl}_{2}^{-} \cdot+\mathrm{H}_{2} \mathrm{O}, \quad$ and $\mathrm{Cl}_{2}^{-} \cdot+\mathrm{S}_{2} \mathrm{O}_{8}^{2-}$. The $k_{-4}\left[\mathrm{H}_{2} \mathrm{O}\right] / K_{5}$ and $k_{8}\left[\mathrm{H}_{2} \mathrm{O}\right]$ were obtained from linear least squares fit of the slopes of the $k_{\text {obs }}$ versus $\left[\mathrm{S}_{2} \mathrm{O}_{8}^{2-}\right]$ analysis with respect to $1 /\left[\mathrm{Cl}^{-}\right]$.

\section{Preferred Values}

$$
k_{8}\left[\mathrm{H}_{2} \mathrm{O}\right]<(1.3 \pm 0.1) \times 10^{3} \mathrm{~s}^{-1} \text {. }
$$

\section{Comments on Preferred Values}

Previous measurements of this rate constant are higher than the recent ones. Yu and Barker's result is consistent with what Jacobi et al. ${ }^{50}$ found by using similar experimental technique and analytical method. The result of Buxton et al. ${ }^{12}$ is astonishingly close to that of McElroy. ${ }^{49}$ It is unclear why such a discrepancy exists between the results obtained by laser flash photolysis and pulse radiolysis. The reaction of $\mathrm{Cl} \cdot$ and $\mathrm{H}_{2} \mathrm{O}$ was not included in the chemical mechanism of Wagner et al.'s analysis. ${ }^{52}$ As to the result of McElroy, ${ }^{49}$ Jacobi et al. ${ }^{50}$ believed that the second-order rate constant $(3.1 \pm 0.1) \times 10^{9} \mathrm{M}^{-1} \mathrm{~s}^{-1}$ used by McElroy ${ }^{49}$ should influence the measured rate constant, because the decay profile of $\mathrm{Cl}_{2}^{-}$- was considered a mixed first- and secondorder procedure. Jacobi et al. ${ }^{50}$ also suggested that $k_{8}\left[\mathrm{H}_{2} \mathrm{O}\right]$ is slower than previously thought. They estimated the Gibbs free energy of the intermediate species to explain their results. Here the range of $k_{8}\left[\mathrm{H}_{2} \mathrm{O}\right]$ is given as the preferred value, because reaction (8) is rather slow despite the differences in reported values. 
TABLE 14. Rate constant data of $k_{9}$

\begin{tabular}{lcccc}
\hline \hline$k_{9}\left(\mathrm{M}^{-1} \mathrm{~s}^{-1}\right)$ & Method & $p \mathrm{H}$ & Reference & Notes \\
\hline$(1.4 \pm 0.3) \times 10^{5}$ & PR & $1-3$ & $1978^{73}$ & $\mathrm{a}$ \\
$4.1 \times 10^{4}$ & PR & 0 & $1989^{74}$ & $\mathrm{~b}$ \\
$7.0 \times 10^{5}$ & N.A. & N.A. & $1996^{75}$ & $\mathrm{c}$ \\
$(1.4 \pm 0.2) \times 10^{6}$ & LFP & 2 & $2003^{6}$ & $\mathrm{~d}$ \\
\hline
\end{tabular}

\subsection{1. $k_{9}, \mathrm{Cl}_{2}^{-} \cdot+\mathrm{H}_{2} \mathrm{O}_{2} \rightarrow \mathrm{HO}_{2} \cdot+\mathrm{H}^{+}+\mathrm{Cl}^{-}$}

Notes (Table 14)

a Hasegawa and Neta (1978), ${ }^{73} \quad k_{9}=(1.4 \pm 0.3)$ $\times 10^{5} \mathrm{M}^{-1} \mathrm{~s}^{-1}$.

Hasegawa and $\mathrm{Neta}^{73}$ monitored the decay of $\mathrm{Cl}_{2}^{-} \cdot$ both in the absence and presence of at least four various concentrations of $\mathrm{H}_{2} \mathrm{O}_{2}$. From the plot of the pseudo-first-order rate constants of $\mathrm{Cl}_{2}^{-}$- decay versus $\left[\mathrm{H}_{2} \mathrm{O}_{2}\right], k_{9}$ was derived with $20 \%$ uncertainty. The system contains $\mathrm{S}_{2} \mathrm{O}_{8}^{2-}$ and $\mathrm{Cl}^{-}$to generate $\mathrm{Cl}_{2}^{-}$- in the absence of $\mathrm{H}_{2} \mathrm{O}_{2}$. When $\mathrm{H}_{2} \mathrm{O}_{2}$ was added, it was suggested that more reactions among $\mathrm{H}_{2} \mathrm{O}_{2}$, $\mathrm{Cl} \cdot \mathrm{HO} \cdot \mathrm{SO}_{4}^{-} \cdot \mathrm{Cl}_{2}^{-} \cdot$, and $\mathrm{S}_{2} \mathrm{O}_{8}^{2-}$ take place. It was unclear whether these reactions were taken into account in the pseudo-first-order derivation. The complicated interference of other reactions might be the explanation of the discrepancy between their result and that by Yu and Barker. ${ }^{6}$

${ }^{\mathrm{b}}$ Elliot (1989), ${ }^{74} k_{9}=4.1 \times 10^{4} \mathrm{M}^{-1} \mathrm{~s}^{-1}$.

This result is even smaller than that of Hasegawa and Neta. ${ }^{73}$ The first-order decay of $\mathrm{Cl}_{2}^{-} \cdot$ was mainly contributed to the reaction of $\mathrm{Cl}_{2}^{-}$. with the impurity of perchloric acid, whereas the reaction of $\mathrm{Cl}_{2}^{-}$and $\mathrm{H}_{2} \mathrm{O}_{2}$ was only a minor component. The $k_{9}$ was measured in deoxygenated solution containing $1 \mathrm{M}$ hydrochloric acid and 1 or $2 \mathrm{M}$ hydrogen peroxide. Presumably, this value was obtained by fitting the $\mathrm{Cl}_{2}^{-} \cdot$ profile by least squares regression.

${ }^{c}$ Jacobi et al. (1996), ${ }^{75} k_{9}=3.2 \times 10^{5} \mathrm{M}^{-1} \mathrm{~s}^{-1}$.

It was not explained how $k_{9}$ was measured. From the plot of $\lg (k)$ versus bond dissociation energy (BDE), $\lg k_{9}=5.5$ was reported with no uncertainty. The $k_{9}=3.2$ $\times 10^{5} \mathrm{M}^{-1} \mathrm{~s}^{-1}$ was derived thereafter. However, Warneck ${ }^{76}$ most recently cited this rate constant as $7.0 \times 10^{5} \mathrm{M}^{-1} \mathrm{~s}^{-1}$. It is unclear why the value shown on the original graph was not taken.

${ }^{\mathrm{d}}$ Yu and Barker (2003), ${ }^{6} k_{9}=1.4 \times 10^{6} \mathrm{M}^{-1} \mathrm{~s}^{-1}$.

The $\mathrm{Cl}_{2}^{-} \cdot$ decay consists of $\mathrm{Cl} \cdot+\mathrm{H}_{2} \mathrm{O}, \mathrm{Cl} \cdot+\mathrm{H}_{2} \mathrm{O}_{2}, \mathrm{Cl}_{2}^{-}$. $+\mathrm{H}_{2} \mathrm{O}$, and $\mathrm{Cl}_{2}^{-} \cdot+\mathrm{H}_{2} \mathrm{O}_{2}$. The $k_{10} / K_{5}$ and $k_{9}$ were obtained from the linear least squares fit of the intercepts of the $k_{\text {obs }}$ versus $\left[\mathrm{H}_{2} \mathrm{O}_{2}\right]$ analysis with respect to $1 /\left[\mathrm{Cl}^{-}\right]{ }^{6}$

\section{Preferred Values}

$k_{9}=(6.2 \pm 6.8) \times 10^{5} \mathrm{M}^{-1} \mathrm{~s}^{-1}$.

\section{Comments on Preferred Values}

Elliot's result is not considered in the unweighted average of $k_{9}$, since no analysis detail was given.

\subsection{2. $k_{10}, \mathrm{Cl} \cdot+\mathrm{H}_{2} \mathrm{O}_{2} \rightarrow \mathrm{H}^{+}+\mathrm{Cl}^{-}+\mathrm{HO}_{2}$.}

Notes (Table 15)

${ }^{\mathrm{a}} \mathrm{Yu}$ and Barker (2003), ${ }^{6} k_{10}=(2.0 \pm 0.1) \times 10^{9} \mathrm{M}^{-1} \mathrm{~s}^{-1}$.
TABLE 15. Rate constant data of $k_{10}$

\begin{tabular}{cccccc}
\hline \hline$k_{10} / K_{5}\left(\mathrm{~s}^{-1}\right)$ & $k_{10}\left(\mathrm{M}^{-1} \mathrm{~s}^{-1}\right)$ & Method & $p \mathrm{H}$ & Reference & Notes \\
\hline $1.4 \pm 0.2$ & $(2.0 \pm 0.3) \times 10^{9}$ & LFP & 2 & $2003^{6}$ & $\mathrm{a}$ \\
\hline
\end{tabular}

The reported value of $k_{10}$ is the first experimentally determined rate constant of the $\mathrm{Cl}$ extraction reaction with $\mathrm{H}_{2} \mathrm{O}_{2}$. The $\mathrm{Cl}_{2}^{-} \cdot$ decay is considered to include $\mathrm{Cl} \cdot+\mathrm{H}_{2} \mathrm{O}, \mathrm{Cl}$. $+\mathrm{H}_{2} \mathrm{O}_{2}, \mathrm{Cl}_{2}^{-} \cdot+\mathrm{H}_{2} \mathrm{O}$, and $\mathrm{Cl}_{2}^{-} \cdot+\mathrm{H}_{2} \mathrm{O}_{2}$. The $k_{10} / K_{5}$ and $k_{9}$ were obtained from the linear least squares fit of the intercepts of the $k_{\text {obs }}$ versus $\left[\mathrm{H}_{2} \mathrm{O}_{2}\right]$ analysis with respect to $1 /\left[\mathrm{Cl}^{-}\right] .^{6}$

Preferred Values

$$
k_{10}=(2.0 \pm 0.1) \times 10^{9} \mathrm{M}^{-1} \mathrm{~s}^{-1} \text {. }
$$

\section{Comments on Preferred Values}

This is the first directly determined rate constant of $\mathrm{Cl}$ and $\mathrm{H}_{2} \mathrm{O}_{2}$ reaction in the aqueous phase. The same reaction taking place in the gas is almost ten times slower. ${ }^{13}$ The recommended $K_{5}=(1.4 \pm 0.2) \times 10^{5} \mathrm{M}^{-1}$ is used to derive this result.

\subsection{3. $k_{11}, \mathrm{Cl}_{2}^{-} \cdot+\mathrm{HO}_{2} \cdot \rightarrow \mathrm{O}_{2}+\mathrm{H}^{+}+2 \mathrm{Cl}^{-}$}

Notes (Table 16)

${ }^{\mathrm{a}}$ Gilbert et al. $(1977),{ }^{77} k_{11}=(4.5 \pm 0.5) \times 10^{9} \mathrm{M}^{-1} \mathrm{~s}^{-1}$.

The effect of dose per pulse on the yield of ferric ions obtained from air-saturated solutions of ferrous ions containing various concentrations of chloride ions was investigated. From a computer based analysis of the following 21 occurring reactions:

$$
\begin{gathered}
\mathrm{H} \cdot+\mathrm{O}_{2} \rightarrow \mathrm{HO}_{2} \cdot \\
2 \times 10^{10} \mathrm{M}^{-1} \mathrm{~s}^{-1}, \\
\mathrm{H} \cdot+\mathrm{H} \cdot \rightarrow \mathrm{H}_{2} \\
1.1 \times 10^{10} \mathrm{M}^{-1} \mathrm{~s}^{-1}, \\
\mathrm{H} \cdot+\mathrm{HO} \cdot \rightarrow \mathrm{H}_{2} \mathrm{O} \\
1.5 \times 10^{10} \mathrm{M}^{-1} \mathrm{~s}^{-1}, \\
\mathrm{H} \cdot+\mathrm{HO}_{2} \cdot \rightarrow \mathrm{H}_{2} \mathrm{O}_{2} \\
1.3 \times 10^{10} \mathrm{M}^{-1} \mathrm{~s}^{-1}, \\
\mathrm{HO} \cdot+\mathrm{HO}_{2} \cdot \rightarrow \mathrm{H}_{2} \mathrm{O}_{3} \\
1.18 \times 10^{10} \mathrm{M}^{-1} \mathrm{~s}^{-1}, \\
\mathrm{HO} \cdot+\mathrm{HO}^{-} \rightarrow \mathrm{H}_{2} \mathrm{O}_{2} \\
1.3 \times 10^{10} \mathrm{M}^{-1} \mathrm{~s}^{-1},
\end{gathered}
$$

TABLE 16. Rate constant data of $k_{11}$

\begin{tabular}{cccccc}
\hline \hline$k_{11} \times 10^{-9}\left(\mathrm{M}^{-1} \mathrm{~s}^{-1}\right)$ & Method & $I, M$ & $p \mathrm{H}$ & Reference & Notes \\
\hline $4.5 \pm 0.5$ & PR & 0.2 & $\sim 0.4$ & $1977^{77}$ & $\mathrm{a}$ \\
$1.0 \pm 0.1$ & PR & N.A. & $\sim 1$ & $1980^{64}$ & $\mathrm{~b}$ \\
$\sim 3$ & PR & $1-12$ & $<2$ & $1987^{78}$ & $\mathrm{c}$ \\
\hline
\end{tabular}




$$
\begin{aligned}
& \mathrm{HO} \cdot+\mathrm{Fe}^{2+}+\mathrm{H}^{+} \rightarrow \mathrm{H}_{2} \mathrm{O}+\mathrm{Fe}^{3+} \\
& 2.3 \times 10^{8} \mathrm{M}^{-1} \mathrm{~s}^{-1}, \\
& \mathrm{HO}_{2} \cdot+\mathrm{HO}_{2} \cdot \rightarrow \mathrm{H}_{2} \mathrm{O}+\mathrm{H}_{2} \mathrm{O}_{2} \\
& 1.05 \times 10^{6} \mathrm{M}^{-1} \mathrm{~s}^{-1} \text {, } \\
& \mathrm{HO}_{2} \cdot+\mathrm{Fe}^{3+}+\mathrm{H}^{+} \rightarrow \mathrm{H}_{2} \mathrm{O}_{2}+\mathrm{Fe}^{3+} \\
& 1.0 \times 10^{6} \mathrm{M}^{-1} \mathrm{~s}^{-1} \text {, } \\
& \mathrm{H}_{2} \mathrm{O}_{3}+2 \mathrm{Fe}^{2+}+2 \mathrm{H}^{+} \rightarrow 2 \mathrm{H}_{2} \mathrm{O}+2 \mathrm{Fe}^{2+} \\
& \text { slow, } \\
& \mathrm{H}_{2} \mathrm{O}_{3}+4 \mathrm{Fe}^{2+}+4 \mathrm{H}^{+} \rightarrow 3 \mathrm{H}_{2} \mathrm{O}+4 \mathrm{Fe}^{2+} \\
& \text { slow, } \\
& \mathrm{Cl}_{2}+\mathrm{Fe}^{2+} \rightarrow 2 \mathrm{Cl}^{-}+2 \mathrm{Fe}^{3+} \\
& \text { slow, } \\
& \mathrm{HO} \cdot+\mathrm{Cl}^{-} \rightarrow \mathrm{OH}^{-}+\mathrm{Cl} \cdot \\
& 4.3 \times 10^{9} \mathrm{M}^{-1} \mathrm{~s}^{-1} \text {, } \\
& \mathrm{Cl} \cdot+\mathrm{Cl}^{-} \rightarrow \mathrm{Cl}_{2}^{-} \text {. } \\
& 2.1 \times 10^{9} \mathrm{M}^{-1} \mathrm{~s}^{-1}, \\
& \mathrm{Cl}_{2}^{-} \cdot \rightarrow \mathrm{Cl} \cdot+\mathrm{Cl}^{-} \\
& 1.1 \times 10^{5} \mathrm{M}^{-1} \mathrm{~s}^{-1}, \\
& \mathrm{Cl} \cdot+\mathrm{Fe}^{2+} \rightarrow \mathrm{Cl}^{-}+\mathrm{Fe}^{3+} \\
& 5.9 \times 10^{9} \mathrm{M}^{-1} \mathrm{~s}^{-1}, \\
& \mathrm{Cl}_{2}^{-} \cdot+\mathrm{Fe}^{2+} \rightarrow 2 \mathrm{Cl}^{-}+\mathrm{Fe}^{3+} \\
& 7.4 \times 10^{6} \mathrm{M}^{-1} \mathrm{~s}^{-1}, \\
& \mathrm{Cl}_{2}^{-} \cdot+\mathrm{Cl}_{2}^{-} \cdot \rightarrow 2 \mathrm{Cl}^{-}+\mathrm{Cl}_{2} \\
& 2.1 \times 10^{9} \quad \mathrm{M}^{-1} \mathrm{~s}^{-1} \text {, } \\
& \mathrm{Cl}_{2}^{-} \cdot+\mathrm{HO}_{2} \cdot \rightarrow 2 \mathrm{Cl}^{-}+\mathrm{H}^{+}+\mathrm{O}_{2} \\
& 4.5 \times 10^{9} \mathrm{M}^{-1} \mathrm{~s}^{-1}, \\
& \mathrm{Cl}_{2}^{-} \cdot+\mathrm{H}^{+} \rightarrow 2 \mathrm{Cl}^{-}+\mathrm{H}^{+}, \\
& \mathrm{Cl} \cdot+\mathrm{H} \cdot \rightarrow \mathrm{Cl}^{-}+\mathrm{H}^{+} .
\end{aligned}
$$

The best rate constant $k_{11}=(4.5 \pm 0.5) \times 10^{9} \mathrm{M}^{-1} \mathrm{~s}^{-1}$ was obtained at high dosage.

$$
\begin{aligned}
& \mathrm{b} \quad \text { Navaratnam et al. } \quad(1980),{ }^{64} \quad k_{11}=(1.0 \pm 0.1) \\
& \times 10^{9} \mathrm{M}^{-1} \mathrm{~s}^{-1} \text {. }
\end{aligned}
$$

Single pulses were delivered to oxygen-saturated solutions containing $0.05 \mathrm{M}$ sodium chloride and $0.15 \mathrm{M} \mathrm{HClO}_{4}$, the disappearance of $\mathrm{Cl}_{2}^{-}$- was followed at $340 \mathrm{~nm}$. Three reactions were considered: $\mathrm{Cl}_{2}^{-} \cdot+\mathrm{HO}_{2} \cdot \mathrm{Cl}_{2}^{-} \cdot+\mathrm{Cl}_{2}^{-} \cdot$, and $\mathrm{HO}_{2}$. $+\mathrm{HO}_{2} \cdot$. The reaction rate of $\mathrm{Cl}_{2}^{-} \cdot+\mathrm{HO}_{2} \cdot$ was found insensitive to the whole mechanism. The theoretical log plot of $\left[\mathrm{Cl}_{2}^{-} \cdot{ }^{\cdot}\right]$ versus time was fitted with various combinations of possible values of $k_{11}, 2 k_{6}$, and $k_{5} .{ }^{9}$ The rate constants $k_{11}=(1.0 \pm 0.1) \times 10^{9} \mathrm{M}^{-1} \mathrm{~s}^{-1} \quad$ and $\quad k_{6}=(2.0 \pm 0.2)$

$\times 10^{9} \mathrm{M}^{-1} \mathrm{~s}^{-1}$ were determined, respectively. The discrepancy between this value and the result of Gilbert et al. ${ }^{77}$ was attributed to the complexity of reactions taking place in the system. However, a quantitative revision of such a scheme was not offered.

c Gogolev et al. (1984), ${ }^{78} \quad k_{11}=3 \times 10^{9}-4$ $\times 10^{9} \mathrm{M}^{-1} \mathrm{~s}^{-1}$.

The second-order decay of $\mathrm{Cl}_{2}^{-}$- was considered to include reactions (6) and (11), i.e., $k_{\mathrm{obs}}^{\mathrm{II}}=2 k_{6}+k_{11}\left[\mathrm{HO}_{2} \cdot\right] /\left[\mathrm{Cl}_{2}^{-}\right]$. When $\left[\mathrm{HO}_{2} \cdot\right]=\left[\mathrm{Cl}_{2}^{-} \cdot\right], k_{\text {obs }}^{\text {II }}=2 k_{6}+k_{11}$ was reached. When $2 k_{6}$ was subtracted from $k_{\text {obs }}^{\mathrm{II}}, k_{11}$ was obtained. The accuracy of $k_{6}$ is crucial in determining $k_{11}$. The $k_{6}$ determined in the same work ranged from $1.0 \times 10^{9}$ to 1.85 $\times 10^{9} \mathrm{M}^{-1} \mathrm{~s}^{-1}$.

\section{Preferred Values $k_{11}=(3.1 \pm 1.5) \times 10^{9} \mathrm{M}^{-1} \mathrm{~s}^{-1}$. \\ Comments on Preferred Values}

The preferred value is the unweighted average of all three previous measurements.

\section{Conclusions}

A series of rate constants and equilibrium constants involving $\mathrm{Cl}$ - related free radicals in aqueous solutions obtained in three companion papers ${ }^{6-8}$ are evaluated in relation to literatures. The numerical values shown in Table 1 may not seem too appealing because some of them have quite large uncertainties. However, they reflect the most reliable range of the $k$ or $K$ determined in the past $40 \mathrm{yrs}$ or so.

The purpose of this evaluation is to point out what has been accomplished and what needs to be done in the future. Some of the rate constants and equilibrium constants need more investigation, for instance, $k_{4}, K_{4}, K_{3}$, and $k_{10}$, since there is only one reported value of these specific rate constants or equilibrium constants. The same applies to the rate constants $k_{2}, k_{9}$, and $k_{11}$, because they have a fair range of reported values. In contrast, $K_{5}$ is better defined by recent works. The values of $k_{-4}, k_{5}, k_{-5}$, and $k_{8}$ are well established by past and current results. The $k_{6}$ is well studied, however, the ionic strength effect on $k_{6}$ still needs clarification.

It is biased to reject or prefer certain results when a range of results were reported and not too much information was disclosed on some of the key analyses. The main strategy used in this paper is to consider experimentally directly determined results unless there were serious doubts on the accuracy of them and take the unweighted average of the data as the recommended value. The commentary of the experimental approaches also serves as a brief guidance for future investigation on fast multiple equilibria systems similar to the system reviewed here. 


\section{Acknowledgments}

Thanks go to NASA (Upper Atmospheric Research Program) and NSF (Atmospheric Chemistry Division) for financial support of this work.

\section{References}

${ }^{1}$ Farhataziz and A. B. Ross, Selected Specific Rates of Reactions of Transients from Water in Aqueous Solutions. III. Hydroxyl Radical and Perhydroxyl Radical and Their Radical Ions, NSRDS-NBS-59, 1977, 131 pp.

${ }^{2}$ A. B. Ross and P. Neta, Rate Constants for Reactions of Inorganic Radicals in Aqueous Solution, NSRDS-NBS-65, 1979, 62 pp.

${ }^{3}$ P. Neta, R. E. Huie, and A. B. Ross, J. Phys. Chem. Ref. Data 17, 1027 (1988).

${ }^{4}$ G. V. Buxton, C. L. Greenstock, W. P. Helman, and A. B. Ross, J. Phys. Chem. Ref. Data 17, 513 (1988).

${ }^{5}$ A. B. Ross, B. H. J. Bielski, G. V. Buxton, D. E. Cabelli, C. L. Greenstock, W. P. Helman, R. E. Huie, and P. Neta, NDRL/NIST Solution Kinetics Database, NIST Standard Reference Database 40, 1.0th ed. (National Institute of Science and Technology, Gaithersburg, MD, 1992).

${ }^{6}$ X.-Y. Yu and J. R. Barker, J. Phys. Chem. A 107, 1313 (2003)

${ }^{7}$ X.-Y. Yu and J. R. Barker, J. Phys. Chem. A 107, 1325 (2003).

${ }^{8}$ X.-Y. Yu, Z.-C. Bao, and J. R. Barker, J. Phys. Chem. A 108, 295 (2004).

${ }^{9}$ G. G. Jayson, B. J. Parsons, and A. J. Swallow, J. Chem. Soc., Faraday Trans. I 69, 1597 (1973).

${ }^{10}$ D. Wu, D. Wong, and B. D. Bartolo, J. Photochem. 14, 303 (1980).

${ }^{11}$ D. J. Adams, S. Barlow, G. V. Buxton, T. N. Malone, and G. A. Salmon, J. Chem. Soc., Faraday Trans. I 91, 3303 (1995).

${ }^{12}$ G. V. Buxton, M. Bydder, and G. A. Salmon, J. Chem. Soc. Faraday Trans. I 94, 653 (1998).

${ }^{13}$ R. Atkinson, D. L. Baulch, R. A. Cox, J. R. F. Hampson, J. A. Kerr, M. J. Rossi, and J. Troe, J. Phys. Chem. Ref. Data 29, 167 (2000).

${ }^{14}$ D. M. Stanbury (private communication, 2003).

${ }^{15}$ M. S. Matheson and L. M. Dorfman, Pulse Radiolysis, Research Monograph in Radiation Chemistry (M. I. T. Press, Cambridge, MA, 1969).

${ }^{16}$ I. Kraljíc and C. N. Trumbore, J. Am. Chem. Soc. 87, 2547 (1965).

${ }^{17}$ J. Rabani and M. S. Matheson, J. Phys. Chem. 70, 761 (1966).

${ }^{18}$ D. Behar, G. Czapski, J. Rabani, L. M. Dorfman, and H. A. Schwartz, J. Phys. Chem. 74, 3209 (1970).

${ }^{19}$ H. A. Schwarz, J. Phys. Chem. 66, 255 (1962).

${ }^{20}$ H. Fricke and J. K. Thomas, Radiat. Res. Suppl. 4, 35 (1964).

${ }^{21}$ H. Christensen, K. Sehested, and H. Corfitzen, J. Phys. Chem. 86, 1588 (1982).

${ }^{22}$ J. Rabani, in Radiation Chemistry-I., edited by R. F. Gould (American Chemical Society, Washington, D.C., 1968), p. 131.

${ }^{23}$ A. J. Elliot and G. V. Buxton, J. Chem. Soc., Faraday Trans. 88, 2465 (1992).

${ }^{24}$ C. Ferradini and A. M. Koulkès-Pujo, J. Chim. Phys. 60, 1310 (1963).

${ }^{25}$ J. K. Thomas, Trans. Faraday Soc. 61, 702 (1965).

${ }^{26}$ G. V. Buxton, Trans. Faraday Soc. 65, 2150 (1969).

${ }^{27}$ W. A. Armstrong, Can. J. Chem. 47, 3737 (1969).

${ }^{28}$ G. Scholes and R. L. Willson, Trans. Faraday Soc. 63, 2983 (1967).

${ }^{29}$ J. H. Baxendale and A. A. Khan, Int. J. Radiat. Phys. Chem. 1, 11 (1969).

${ }^{30}$ Z. P. Kachanova and Y. N. Kozlov, Russ. J. Phys. Chem. 47, 1190 (1973).

${ }^{31}$ M. Hatada, I. Kraljic, A. E. Samahy, and C. N. Trumbore, J. Phys. Chem. 78, 888 (1974).

${ }^{32}$ G. Merényi and J. S. Lind, J. Am. Chem. Soc. 102, 5830 (1980).

${ }^{33}$ J. H. Baxendale, J. Chem. Soc., Faraday Trans. 1 69, 1665 (1973).

${ }^{34}$ C. L. Greenstock and R. H. Wiebe, in Oxygen and Oxy-radicals in Chemistry and Biology, edited by M. A. J. Rodgers and E. L. Powers (Academic, New York, 1980), p. 119.

${ }^{35}$ R. L. Willson, C. L. Greenstock, G. E. Adams, R. Wageman, and L. M. Dorfman, Int. J. Radiat. Phys. Chem. 3, 211 (1971).
${ }^{36}$ M. Burton and K. C. Kurien, J. Phys. Chem. 63, 899 (1959).

${ }^{37}$ R. W. Mattews and D. F. Sangster, J. Phys. Chem. 69, 1938 (1965).

${ }^{38}$ A. E. Grigorév, I. E. Makarov, and A. K. Pikaev, High Energy Chem. 21, 99 (1987).

${ }^{39}$ M. Anbar and J. K. Thomas, J. Phys. Chem. 68, 3829 (1964).

${ }^{40}$ I. Kraljíc, in Chemistry of Ionization and Excitation, edited by G. R. A. Johnson and G. Scholes (Taylor and Francis, London, 1967), p. 303.

${ }^{41}$ G. Hughes and H. A. Makada, Int. J. Radiat. Phys. Chem. 1, 325 (1969).

${ }^{42}$ D. Pramanick, J. Sarkar, and R. Bhattacharyya, J. Poly. Sci. A: Poly. Chem. 26, 2457 (1988).

${ }^{43}$ P. Maruthamuthu and P. Neta, J. Phys. Chem. 81, 937 (1977).

${ }^{44}$ J. F. Ward and L. S. Myers, Jr., Rad. Res. 26, 483 (1965).

${ }^{45}$ F. J. Hart, J. K. Thomas, and S. Gordon, Rad. Res. Suppl. 4, 74 (1964).

${ }^{46}$ L. S. Myers, Jr., M. L. Hollis, and L. M. Theard, in Advances in Chemistry Series, edited by E. J. Hart (American Chemical Society, Washington, D.C., 1968), p. 345

${ }^{47}$ H. Ogura and W. H. Hamill, J. Phys. Chem. 77, 2952 (1973).

${ }^{48}$ U. K. Kläning and T. Wolff, Ber. Bunsenges. Phys. Chem. 89, 243 (1985).

${ }^{49}$ W. J. McElroy, J. Phys. Chem. 94, 2435 (1990).

${ }^{50}$ H.-W. Jacobi, H. Herrmann, and R. Zellner, Ber. Bunsenges. Phys. Chem. 101, 1909 (1997).

${ }^{51}$ V. Nagarajan and R. W. Fessenden, J. Phys. Chem. 89, 2330 (1985).

${ }^{52}$ I. Wagner, J. Karthäuser, and H. Strehlow, Ber. Bunsenges. Phys. Chem. 90, 861 (1986).

${ }^{53}$ A. Iwata and C. Yamanaka, Anal. Chim. Acta 277, 25 (1993).

${ }^{54}$ A. A. Zansokhova, S. A. Kabakchi, and A. K. Pikaev, High Energy Chem. 11, 50 (1977).

${ }^{55}$ R. E. Huie and C. L. Clifton, J. Phys. Chem. 94, 8561 (1990).

${ }^{56}$ H.-W. Jacobi, F. Wicktor, H. Herrmann, and R. Zellner, Int. J. Chem. Kin. 31, 169 (1999).

${ }^{57}$ H. A. Schwarz and R. W. Dodson, J. Phys. Chem. 88, 3643 (1984).

${ }^{58}$ M. E. Langmuir and E. Hayon, J. Phys. Chem. 71, 3808 (1967)

${ }^{59}$ L. K. Patterson, K. M. Bansal, G. Bogan, G. A. Infanta, E. J. Fendler, and J. H. Fendler, J. Am. Chem. Soc. 94, 9028 (1972).

${ }^{60}$ A. T. Thornton and G. S. Laurence, J. C. S. Dalton 8, 804 (1973).

${ }^{61}$ T. P. Zhestkova and A. K. Pikaev, Bull. Akad. Nauk SSSR, Div. Chem. Sci. 23, 877 (1974).

${ }^{62}$ R. J. Woods, B. Lesigne, L. Giles, C. Ferradini, and J. Pucheault, J. Phys. Chem. 79, 2700 (1975).

${ }^{63}$ R. K. Broszkiewicz, Bull. Acad. Polonaise Sciences Sér. Sci. Chim. XXIV, 123 (1976).

${ }^{64}$ S. Navaratnam, B. J. Parsons, and A. J. Swallow, Radiat. Phys. Chem. 15, 159 (1980).

${ }^{65}$ A. Y. Gogolev, I. E. Makarov, and A. K. Pikaev, High Energy Chem. 18, 390 (1984).

${ }^{66}$ A. Slama-Schwok and J. Rabani, J. Phys. Chem. 90, 1176 (1986).

${ }^{67}$ C. Lierse, J. C. Sullivan, and K. H. Schmidt, Inorg. Chem. 26, 1408 (1987).

${ }^{68}$ A. J. Hynes and P. H. Wine, J. Chem. Phys. 89, 3565 (1988).

${ }^{69}$ Z.-C. Bao, Ph.D. thesis, University of Michigan, Michigan, 1997.

${ }^{70}$ M. L. Alegre, M. Gerones, J. A. Rosso, S. G. Bertolotti, A. M. Braun, D. O. Martire, and M. C. Gonzalez, J. Phys. Chem. 104, 3117 (2000).

${ }^{71}$ C. George and J. M. Chovelon, Chemosphere 47, 385 (2002).

${ }^{72}$ G. A. Poskrebyshev, Zh. Fiz. Khim. 71, 1360 (1997).

${ }^{73}$ K. Hasegawa and P. Neta, J. Phys. Chem. 82, 854 (1978).

${ }^{74}$ A. J. Elliot, Radiat. Phys. Chem. 34, 753 (1989).

${ }^{75}$ H.-W. Jacobi, H. Herrmann, and R. Zellner, in Homogeneous and Heterogeneous Chemical Processes in the Troposphere, edited by P. Mirabel (Brussels, 1996), p. 172.

${ }^{76}$ P. Warneck, Phys. Chem. Chem. Phys. 1, 5471 (1999).

${ }^{77}$ C. W. Gilbert, R. B. Ingalls, and A. J. Swallow, Radiat. Phys. Chem. 10, 221 (1977).

${ }^{78}$ A. V. Gogolev, V. P. Shilov, A. M. Fedoseev, I. E. Makarov, and A. K. Pikaev, Bull. Akad. Nauk SSSR, Div. Chem. Sci. 36, 1148 (1987).

${ }^{79}$ B. C. Faust, C. Anastasio, J. M. Allen, and T. Arakaki, Science 260, 73 (1993). 